\title{
Review Article \\ Cardiovascular Screening for the Asymptomatic Patient with Diabetes: More Cons Than Pros
}

\author{
Konstantinos Makrilakis and Stavros Liatis \\ First Department of Propaedeutic Internal Medicine, National and Kapodistrian University of Athens Medical School, \\ Laiko General Hospital, Athens, Greece \\ Correspondence should be addressed to Konstantinos Makrilakis; kmakrila@med.uoa.gr
}

Received 26 June 2017; Revised 17 October 2017; Accepted 5 November 2017; Published 14 December 2017

Academic Editor: Kim Connelly

Copyright ( ) 2017 Konstantinos Makrilakis and Stavros Liatis. This is an open access article distributed under the Creative Commons Attribution License, which permits unrestricted use, distribution, and reproduction in any medium, provided the original work is properly cited.

\begin{abstract}
Diabetes mellitus is associated with an increased risk of coronary heart disease (CHD) morbidity and mortality. Although it frequently coexists with other cardiovascular disease (CVD) risk factors, it confers an increased risk for CVD events on its own. Coronary atherosclerosis is generally more aggressive and widespread in people with diabetes (PWD) and is frequently asymptomatic. Screening for silent myocardial ischaemia can be applied in a wide variety of ways. In nearly all asymptomatic PWD, however, the results of screening will generally not change medical therapy, since aggressive preventive measures, such as control of blood pressure and lipids, would have been already indicated, and above all, invasive revascularization procedures (either with percutaneous coronary intervention or coronary artery bypass grafting) have not been shown in randomized clinical trials to confer any benefit on morbidity and mortality. Still, unresolved issues remain regarding the extent of the underlying ischaemia that might affect the risk and the benefit of revascularization (on top of optimal medical therapy) in ameliorating this risk in patients with moderate to severe ischaemia. The issues related to the detection of coronary atherosclerosis and ischaemia, as well as the studies related to management of CHD in asymptomatic PWD, will be reviewed here.
\end{abstract}

\section{Introduction}

The prevalence of diabetes mellitus (DM) is increasing and is reaching epidemic proportions worldwide, as the population becomes older and is less active and more obese. According to recent estimates from the International Diabetes Federation (IDF), approximately 415 million people were affected by DM globally in 2015 , with the projections being very dire for the future $(642$ million people are predicted for the year 2040) [1]. The economic burden of treating diabetes and its complications is likewise enormous [2].

People with diabetes (PWD) are at increased risk of developing both micro- and macrovascular complications [3], which are diminished with proper glycaemic treatment [4]. Compared with people without diabetes, men and, especially, women with diabetes have decreased life expectancy (six to eight years less) [5]. One needs to keep in mind though that these people do not die from diabetes per se but rather from cardiovascular disease (CVD) $[6,7]$. At the time of diagnosis of type 2 diabetes (T2D), many patients already have one or more additional risk factors for macrovascular disease (obesity, hypertension, dyslipidaemia, and smoking) and many have evidence of overt atherosclerosis (previous myocardial infarction (MI), ischaemic stroke, ischaemic changes on electrocardiogram (ECG), or peripheral vascular disease) [8].

The relationship linking DM to CVD is however more complex and multifaceted in nature [9]. Apart from the above-mentioned classical CVD risk factors, studies have reported that several other factors, including increased oxidative stress, increased coagulability, low-grade inflammation, endothelial dysfunction, and autonomic neuropathy, are often present in patients with DM and may directly contribute to the development of CVD [10]. It has been shown that endothelium-dependent epicardial coronary artery vasodilation in response to acetylcholine [11] or physiological stimuli [12] is impaired in diabetic patients, suggesting that endothelial dysfunction (known to be an independent 
predictor of cardiovascular events [13]) occurs before the development of overt atherosclerosis in these persons. Furthermore, nonobstructive coronary atherosclerosis (defined as either $<50 \%$ luminal narrowing, $<20 \%$ narrowing, or unimpaired coronary blood flow, depending on the study [14]) is also frequently associated with both DM $[15,16]$ and vascular dysfunction [17], thus independently contributing to the increased CVD event risk [18]. Collectively, the high rates of CVD risk factors and direct biological effects of diabetes on the cardiovascular system place diabetic persons at very increased risk of developing CVD [9].

Coronary heart disease (CHD) is the leading cause of morbidity and mortality in PWD, as it is implicated in $60 \%-80 \%$ of deaths and is $2-4$ times more common in the diabetic compared to the general population [19]. CHD has certain unique characteristics in diabetic persons, making it more serious and aggressive. It is often more extensive, affecting multiple, more peripheral, and smaller blood vessels [20], accompanied by generalized endothelial dysfunction and microcirculatory disorders in the myocardium [21], thus resulting in more difficult revascularization procedures, compared to the nondiabetic individuals [22]. The atherosclerotic plaque of diabetic patients is also infiltrated by macrophages more extensively and has more lipid components, making it more unstable and vulnerable to rupture [23]. Furthermore, CHD in PWD occurs at a younger age (on average 15 years earlier) [24] and has a higher mortality in diabetic women [25]. Also, CHD in diabetes is more often silent (not producing clinical subjective symptoms), which makes it difficult to diagnose early $[26,27]$. It is believed that this fact-the nonperception of pain that results in silent ischaemia, atypical symptoms, or even silent myocardial infarctions-is, at least in part, due to autonomic denervation of the heart [28]. Multivessel CHD is also common in asymptomatic patients with diabetes, particularly those with two or more coronary risk factors other than diabetes [29].

Due to all these special characteristics, the prognosis of $\mathrm{CHD}$ in diabetic persons is worse than in nondiabetic ones: even after myocardial revascularization (coronary artery bypass grafting (CABG) or percutaneous coronary intervention (PCI) with stent placement), restenosis rates and perioperative or long-term outcomes are worse in diabetic individuals $[22,30,31]$. Thus, it is considered by many that DM is equivalent to established CHD in terms of cardiovascular prognosis, that is, that PWD with no history of $\mathrm{CHD}$ has the same risk of developing a cardiovascular event in the future compared to nondiabetic ones who already have CHD manifestations. This statement was actually based on a few studies [32-34], in which T2D patients without history of CHD events at baseline showed similar coronary mortality as nondiabetic patients who had a previous coronary event. On the other hand, recent studies [35] and meta-analyses [36] indicate that a significant part of PWD are in a lower cardiovascular risk category (e.g., men younger than 35 years of age, women younger than 45 years, and patients with diabetes duration of less than 10 years without other risk factors) [37], and recent guidelines do not anymore consider diabetes as a CHD risk equivalent, but recommend cardiovascular risk stratification for primary and secondary prevention $[38,39]$.
The risk of developing CHD is actually beginning to increase from the prediabetic phase, prior to the clinical manifestation of DM. Many of the atherogenic risk factors are present already in the prediabetic phase, as most individuals have characteristics of the metabolic (insulin resistance) syndrome, which increases CVD risk [40]. The CHD risk in PWD varies widely with the intensity of these risk factors. The evidence is strongest for hypertension, elevated lowdensity lipoprotein cholesterol, smoking, the metabolic syndrome, hyperglycaemia, and microalbuminuria, and it is generally recommended that all these should be aggressively treated, so that the risk of future CHD events will be decreased [41].

Taking all this information into consideration, there is no doubt that, compared to individuals without diabetes, those with diabetes have a higher prevalence of $\mathrm{CHD}$, a greater extent of coronary ischaemia, and are more likely to suffer a myocardial infarction and silent myocardial ischaemia. Furthermore, the risk of asymptomatic CVD in diabetic persons is quite high [42]. Although there is a preponderance of evidence that in the setting of an acute coronary syndrome an invasive approach using coronary revascularization has a morbidity and mortality benefit [43], the optimal strategy for detection and management of CHD in stable, asymptomatic persons is not very well elucidated [44]. The extent to which routine revascularization reduces death or MI, or improves quality of life (QoL) in patients with stable ischaemic heart disease (SIHD), on top of guideline-directed optimal medical therapy (GDOMT), represents one of the greatest uncertainties in cardiology [45]. Accordingly, although screening to detect early CHD and provide targeted treatment for patients with possible evidence of $\mathrm{CHD}$ would seem reasonable, there are multiple issues that must be addressed concerning the possible role of screening in such patients (e.g., the accuracy of screening tests, how easily testing can be performed, the safety and costs of testing, and available interventions that improve outcomes after screening).

In this context, issues related to the detection of coronary atherosclerosis and ischaemia, as well as the studies related to management of CHD in asymptomatic patients with diabetes, will be reviewed here.

\section{Presymptomatic Screening for CHD in Diabetes}

Screening is defined as an attempt to identify an asymptomatic, unrecognized disease before its clinical presentation or risk factor for it. This is done by history taking (e.g., asking about smoking), physical examination (e.g., a blood pressure measurement), laboratory test (e.g., serum cholesterol measurement), or another procedure (e.g., a cervical Pap-test in women) that can be applied to asymptomatic people. It is thus hoped that screening may improve the effectiveness of secondary prevention, which aims at preventing the progression and clinical onset of the disease in people without yet clinical signs, by identifying those who already have the disease without knowing, and who are likely to benefit from the early diagnosis. 
In 1971, Archie Cochrane, considered one of the originators of Randomized Clinical Trials and Evidence-Based Medicine, wrote in his groundbreaking paper on validation of medical screening procedures: "If a patient asks a medical practitioner for help, the doctor does the best he can. He is not responsible for defects in medical knowledge. If, however, the practitioner initiates screening procedures, he is in a very different situation. He should have conclusive evidence that screening can alter the natural history of disease in a significant proportion of those screened." [46].

A unique requirement for screening in secondary prevention is that treatment of early, asymptomatic disease must be superior to treatment of the disease when it would have been diagnosed in the usual course of events, when a patient will seek medical care for symptoms. If the outcome in the two situations is the same, screening does not add value.

Thus, in the case of asymptomatic CHD in PWD, it is not enough just to find early that they suffer from CHD, but also to prove that early, asymptomatic diagnosis will lead to a reduction in cardiac morbidity and/or mortality, by applying some form of intervention, other than the one(s) that is (are) already recommended and should be applied anyway (i.e., control of the CHD risk factors). Given the increased risk of CHD in the case of PWD, GDOMT involves the use of "disease-modifying" pharmacological interventions, including statins, inhibitors of the renin-angiotensin-aldosterone axis, and possibly antiplatelet agents, that individually have been shown to reduce death and MI in placebo-controlled trials, together with lifestyle interventions, such as cigarette smoking cessation, prudent diet, and regular exercise [45]. Control of hyperglycaemia has also been proven to be beneficial, especially if started early, in both types of diabetes $[4,47]$.

The goal of CHD treatment is to alleviate symptoms of angina (if present) and, most importantly, to protect the patient from subsequent serious complications, that is, MI, heart failure, or even death. Although angina has long been considered the cardinal symptom of myocardial ischaemia and $\mathrm{CHD}$, silent (asymptomatic) myocardial ischaemia is the most common manifestation of CHD, accounting for more than $75 \%$ of ischaemic episodes during daily life (both in people with known CHD and in those with unknown disease) [48]. Silent myocardial ischaemia is defined as the presence of objective evidence of myocardial ischaemia in the absence of chest discomfort or another anginal equivalent symptom (e.g., dyspnoea, nausea, and diaphoresis). Objective evidence of silent myocardial ischaemia in PWD may be obtained through several ways [49], and its prevalence depends significantly on the method of screening and what test result is considered diagnostic for CHD. The available screening tests can be divided into invasive (e.g., coronary artery angiography) or noninvasive and functional or anatomic ones [50] (Table 1). Since catheter-based coronary artery angiography [51] is expensive and is associated with a small risk of serious complications that are directly related to its invasive nature and to the use of iodinated contrast media (such as atheroembolism, bleeding, myocardial infarction, ventricular tachyarrhythmias, renal failure, stroke, and death), noninvasive techniques, are usually preferred first and gaining great popularity. Furthermore, coronary angiography is also hampered by technical limitations, such as the occasional inability to optimally visualize a particular location and also by providing information only about the contour of the vascular lumen and not the components of the vascular wall, which are not visualized. Atherosclerotic plaques develop initially in the vascular wall and can thus be missed or their significance underestimated by coronary lumen angiography, which is not generally recommended for screening purposes [52].

The following tests are available for the noninvasive diagnosis of CHD:

(i) Exercise ECG, generally using a treadmill and standardized protocols [53-55]

(ii) Radionuclide myocardial perfusion imaging (rMPI) using either exercise or pharmacologic (dobutamine, adenosine, or dipyridamole) stress and imaging with either single photon emission computed tomography (SPECT) $[27,56]$ or positron emission tomography (PET) [57]

(iii) Echocardiography using either exercise or pharmacologic stress $[58,59]$

(iv) Cardiac magnetic resonance (CMR) imaging [60]

(v) Coronary computed tomography, either for detection of coronary artery calcifications (CAC) or for assessing coronary artery stenosis with coronary computed tomography angiography (CCTA) [61]

(vi) Hybrid imaging, using either SPECT/CT, PET/CT, or PET/MRI [62]

Stress testing provides physiologic evidence of clinically significant coronary artery stenoses by demonstrating the effects of diminished coronary flow reserve on symptoms, characteristic changes on the ECG, myocardial perfusion defects on scintigraphy or PET, or regional wall motion abnormalities on echocardiography. Nondiagnostic findings or ambiguity on the results may suggest the need for direct (anatomic) assessment of the coronary artery lumen with invasive (or noninvasive) coronary arteriography.

Stress testing (either with exercise or pharmacologic provocation) combined with radionuclide myocardial perfusion imaging (rMPI) is more sensitive than exercise stress testing alone (despite the latter's simplicity, wide availability, and low cost) for the diagnosis of $\mathrm{CHD}$, in both people with and without diabetes [63]. rMPI is particularly appealing for screening asymptomatic PWD [64] and has a central role in the diagnosis and risk stratification of diabetic patients with suspected CHD, in particular for the evaluation of silent ischaemia $[56,65]$. The reported prevalence of silent myocardial ischaemia on rMPI in DM patients has been disparate among studies [49]. Observational studies performed more than a decade ago reported a prevalence ranging from $16 \%$ to $59 \%$, with approximately $20 \%$ of patients having highrisk findings [27, 66], whereas in more recent studies, a much lower prevalence of any perfusion defect or LV function 
TABLE 1: Screening methods for detecting asymptomatic coronary artery ischaemia in patients with diabetes.

\begin{tabular}{|c|c|c|}
\hline Screening methods & Detection of prevalent CHD & Comments \\
\hline \multicolumn{3}{|c|}{ Functional tests } \\
\hline Resting electrocardiogram (ECG) & Low sensitivity and specificity & Widely available, very low cost \\
\hline Exercise ECG & $\begin{array}{l}\text { Moderate sensitivity (45-61\%) and specificity } \\
\qquad(70-90 \%)\end{array}$ & $\begin{array}{l}\text { Relatively low cost, widely available } \\
\text { Many patients unable to exercise } \\
\text { Some have uninterpretable baseline ECGs }\end{array}$ \\
\hline $\begin{array}{l}\text { Radionuclide single proton emission } \\
\text { computed tomography (SPECT) } \\
\text { myocardial perfusion imaging (MPI) }\end{array}$ & $\begin{array}{l}\text { Good sensitivity ( } 80-90 \%) \text { and specificity } \\
\text { (75-90\%) } \\
\text { The most widely used test to assess silent } \\
\text { myocardial ischaemia }\end{array}$ & $\begin{array}{c}\text { Moderate to high cost } \\
\text { Widely available } \\
\text { High negative predictive value (95\%) } \\
\text { Image quality affected by body habitus and } \\
\text { large breasts } \\
\text { Screening of asymptomatic patients not } \\
\text { prognostically useful unless high-risk } \\
\text { patients are selected }\end{array}$ \\
\hline $\begin{array}{l}\text { Myocardial perfusion imaging (MPI) } \\
\text { with positron emission tomography } \\
\text { (PET) }\end{array}$ & $\begin{array}{l}\text { High sensitivity for myocardial viability studies } \\
\text { Accurate global and regional measurements of } \\
\text { myocardial perfusion, blood flow, and function } \\
\text { at stress and rest in a single study }\end{array}$ & $\begin{array}{l}\text { Better image quality because of higher spatial } \\
\text { resolution, less scattered, and fewer attenuation } \\
\text { artifacts } \\
\text { Lower radiation exposure than SPECT } \\
\text { Costly, not universally available }\end{array}$ \\
\hline $\begin{array}{l}\text { Stress echocardiography } \\
\text { (i) Exercise stress echo } \\
\text { (ii) Pharmacologic stress echo } \\
\text { (dobutamine, adenosine, and } \\
\text { dipyridamole) }\end{array}$ & $\begin{array}{l}\text { The sensitivity and specificity are satisfactory } \\
\qquad(80-85 \%) \\
\text { Able to assess LV function and valvular } \\
\text { abnormalities }\end{array}$ & $\begin{array}{c}\text { Low cost, widely available } \\
\text { Operator dependent } \\
\text { Difficulty in interpreting the images in obese } \\
\text { persons }\end{array}$ \\
\hline
\end{tabular}

\begin{tabular}{|c|c|c|}
\hline \multicolumn{3}{|c|}{ Anatomic (imaging) techniques } \\
\hline Coronary artery calcium score (CAC) & $\begin{array}{c}\text { CAC more prevalent in people with diabetes } \\
\text { than nondiabetes } \\
\text { Closely associated with total coronary artery } \\
\text { atherosclerotic plaque burden } \\
\text { Predicts incident ischaemia, CHD morbidity } \\
\text { and mortality }\end{array}$ & $\begin{array}{c}\text { Moderate to high cost } \\
\text { No differentiation between obstructive and } \\
\text { nonobstructive CHD } \\
\text { Up to 25\% of patients have minimal or no CAC } \\
\text { at the time of screening }\end{array}$ \\
\hline $\begin{array}{l}\text { Multidetector-row computed } \\
\text { tomography (MRCT) angiography }\end{array}$ & $\begin{array}{l}\text { High sensitivity (83-99\%) and specificity } \\
\qquad(93-98 \%)\end{array}$ & $\begin{array}{c}\text { Good sensitivity, specificity, and negative } \\
\text { predictive value. High radiation doses } \\
\text { High cost }\end{array}$ \\
\hline Magnetic resonance imaging (MRI) & $\begin{array}{l}\text { Good sensitivity (83-90\%) and specificity } \\
\qquad(72-84 \%) \\
\text { Delayed gadolinium hyperenhancement linked } \\
\text { to increased risk of major cardiovascular events } \\
\text { Not adequately investigated }\end{array}$ & $\begin{array}{c}\text { Able to assess myocardial structure and function } \\
\text { and characterize ischemic, inflammatory and } \\
\text { various types of cardiomyopathies } \\
\text { High cost }\end{array}$ \\
\hline
\end{tabular}

abnormality (22\% in DIAD (Detection of Ischemia in Asymptomatic Diabetes) study) [42] or even lower (12.5\%) [67] has been reported. The yield of stress testing in asymptomatic PWDM can be improved by selecting patients based on the pretest clinical risk of CHD, for example, by selecting persons with abnormal ECGs and vascular disease [66] or-if performed-with a high CAC score (a CAC score $>400$ or $>1000$ is predictive of moderate to severe silent myocardial ischaemia on SPECT in diabetic patients $(48 \%$ and $71 \%$ ischaemia, resp.)) [68]. Limitations of the technique include the fact that it is expensive and diagnostic image quality is affected in obese patients, as well as in women and men with large breasts. Also, global reductions in myocardial perfusion, such as in the setting of left main or 3-vessel CHD, can result in balanced reduction and an underestimation of ischaemic burden with myocardial perfusion SPECT.
Several other imaging variables with high diagnostic and prognostic value can also be obtained during SPECT-MPI. Among them, transient ischemic dilation (TID) $[69,70]$, defined as the apparent presence of left ventricular dilation on poststress relative to rest images [71], has been linked to increased CVD risk in the context of reversible myocardial perfusion defects during SPECT-MPI [72, 73]. Specifically for diabetic persons, TID provides independent and incremental prognostic information for the prediction of cardiac death or nonfatal MI [74], and even in the absence of regional myocardial perfusion abnormalities, TID is an important sign of CHD, especially when TID ratio exceeds 1.16 [75].

Furthermore, adverse remodeling of the left ventricle (LV), defined as a change in shape due to CVD, is associated with worse prognosis [76], as shown, for example, with the increased end-systolic volume in patients after myocardial 
infarction [77]. Left ventricular geometry is especially associated with the pathophysiology and symptomatology of congestive heart failure (CHF) [78], usually assessed with echocardiography [79]. Of note, incidental diagnosis of left ventricular systolic dysfunction (LVD) is common in clinical practice. The prevalence of asymptomatic LVD (ejection fraction $(\mathrm{EF})<50 \%)$ is $6.0 \%$ in men and $0.8 \%$ in women of the general population and is twice as common as symptomatic LVD. The timely and definitive exclusion of an ischaemic etiology is central to optimizing care and reducing mortality in this case. Advances in cardiovascular imaging provide many options for imaging of patients with LVD [80]. Gated myocardial perfusion single photon emission computed tomography (SPECT) (MPS) has the ability to provide operator-independent measurements of myocardial perfusion and function in 3 dimensions [81], thus providing more precise information regarding the LV shape [82]. The left ventricular shape index (LVSI), derived as the ratio of maximum 3D short- and long-axis LV dimensions, for end systole and end diastole, has been shown to be an independent predictor of CHF hospitalization [81] and can potentially be used for the detection of ischemia even in the absence of a perfusion defect in the territory of a specific coronary artery [83].

Positron emission tomography (PET) has several clinical and research applications in cardiovascular imaging but is still not widely utilized in routine clinical practice because of nonuniversal availability of PET scanners (cardiac PET tracers are costly and require either an onsite cyclotron or a monthly generator). PET/CT hybrid cameras are superior to PET, SPECT/CT, and SPECT scanners. PET provides better image quality because of higher spatial resolution, less scatter, and fewer attenuation artifacts. ${ }^{18}$ F-FDG PET imaging has high sensitivity for the detection of hibernating/viable myocardium and has replaced Tl-201 SPECT imaging in centers equipped with a PET/CT camera [62]. Myocardial perfusion imaging with PET allows accurate global and regional measurements of myocardial perfusion, myocardial blood flow, and function at stress and rest in a single study session performed in approximately $30 \mathrm{~min}$ $[57,84]$. The noninvasive assessment of coronary flow reserve (CFR $=$ stress divided by rest myocardial blood flow) using PET is a powerful tool that integrates the effects of focal stenosis, diffuse disease, and coronary microvascular function and has been shown that impaired CFR (below the median) was associated with an adjusted 3.2- and 4.9fold increase in the rate of cardiac death for diabetic and nondiabetic persons, respectively $(P=0.0004)$ [85]. The advantages of PET over SPECT include the lower radiation patient exposure (due to the shorter physical half-lives of PET perfusion tracers) and more robust attenuation correction (leading to higher diagnostic accuracy in women and patients with larger body habitus) [86].

Stress echocardiography (either pharmacologic or with exercise) has similar diagnostic accuracy for CHD as stress testing with rMPI [87]. The diagnostic endpoint of exercise and pharmacological stress echocardiography is new or worsening wall motion abnormalities and changes in global LV function during or immediately after stress. In addition to the detection of inducible wall motion abnormalities, most stress echocardiography includes screening images to evaluate resting ventricular function and valvular abnormalities [50]. The presence and extent of resting LV dysfunction and ischaemia found with dobutamine or dipyridamole stress echocardiography are predictive of death, in both diabetic and nondiabetic individuals $[58,59]$. Stress echocardiography is an observer- and patient-dependent procedure, the accuracy of which depends on the experience of the interpreter as well the acoustic windows available during stress testing. The use of intravenous ultrasound contrast agents can improve endocardial border delineation and can result in improved diagnostic accuracy [88].

Another modality that can be used for the evaluation of $\mathrm{CHD}$ is cardiac magnetic resonance (CMR) imaging, which provides an accurate means of assessing myocardial structure and function and enables characterization of the range of myocardial diseases from ischemic to inflammatory and various types of cardiomyopathy [89]. Delayed gadolinium enhancement CMR is able to directly visualize myocardial infarction in vivo [90]. The presence of late gadolinium hyperenhancement as a marker of prior MI in diabetic patients with unsuspected CHD has been linked with a 4fold increased risk of major adverse cardiovascular events and a 7 -fold increased risk of mortality [49].

Histological studies have shown that the extent of coronary artery calcium (CAC) is closely associated with total coronary artery atherosclerotic plaque burden [91]. Furthermore, CAC scores predict incident CHD in the general population [92] and patients affected by type 2 DM harbor larger amounts of CAC than nondiabetic patients of a similar age [93]. Additionally, the extent [94] and prevalence [95] of CAC in patients with type $2 \mathrm{DM}$ asymptomatic for $\mathrm{CHD}$ is similar to that of patients with established CHD but without DM [96]. Interestingly, the extent of CAC has been shown to be associated with the prevalence of inducible ischaemia by SPECT-MPI [97]. Several studies [68, 98, 99], although not all [100], have demonstrated that increased CAC in persons with metabolic syndrome and/or diabetes is associated with increased prevalence of myocardial ischaemia, cardiac events, and mortality. In nondiabetic persons, the CAC score threshold at which the prevalence of ischaemia increases substantially is $>400$ Agatston units [97], although in diabetic patients this threshold has been reported to be lower [93]. Furthermore, sequential CAC imaging has been implemented as a means to assess atherosclerosis progression and progression of CAC has been shown to be a strong predictor of future MI [101]. On the other hand, a high proportion of adults with diabetes have zero or a very low CAC score ( $<10$ Agatston units) $[99,102]$ but a CAC score of zero does not completely exclude CHD (in other words, CAC scoring does not allow differentiation between obstructive and nonobstructive CHD) [103]. In summary, since CAC measurement provides strong risk stratification of patients with diabetes, with an increase in mortality for each increase in CAC score category, is less expensive than SPECT/MPI, and has less radiation exposure, the overall evidence supports the class IIb indication in the 2013 ACC/AHA guidelines, claiming that the use of CAC scanning "may be appropriate" 
for risk stratification and guiding management in the asymptomatic DM patient [104].

Noninvasive coronary angiography can be performed with either multidetector-row CT (MDCT) [105] or magnetic resonance imaging (MRI) techniques, with better sensitivity and specificity for the MDCT compared to cardiac MRI [106]. For patients in whom CHD screening is being performed, CAC scoring and coronary CT angiography can directly identify the presence of atherosclerotic CHD, although neither test is able to provide functional information (i.e., impaired blood flow resulting in ischaemia) [107]. Any benefit of these newer noninvasive CHD screening methods, such as computed tomography and computed tomography angiography, to identify patient subgroups for different treatment strategies remains unproven and is thus not currently routinely recommended for using [108].

\section{Safety of Screening Tests}

It is reasonable and ethical to accept a certain risk for diagnostic tests applied to sick patients when they seek medical advice for specific complaints. However, it is quite another matter to subject presumably healthy people to risks. In such circumstances, the procedure should be particularly safe. This is partly because the chances of finding disease in healthy people are generally low. Thus, concerns have been raised about possible long-term risks with the increasing use of CT scans to screen for CHD. The radiation dose of CT scans varies by type, with a CT scan for coronary calcium on average being the equivalent of about 30 chest X-rays. One estimate of risk projected 29,000 excess cancers as a result of 70 million CT scans performed for various reasons in the United States in 2007 [109]. If these concerns are correct, CT scans used to screen for early CHD in asymptomatic individuals could themselves cause cancer over subsequent decades.

Adverse effects of screening tests include discomfort during the test procedure, risks related to the screening test per se (e.g., allergic reactions, long-term radiation effects, or perforation of coronary vessels during coronary arteriography), false-positive test results (with resulting needless workups and negative labeling effects [inconvenience and expense in obtaining follow-up procedures]), and overdiagnosis.

\section{Studies of Screening for Asymptomatic CHD in Diabetes}

As already stated, the primary purpose of screening for CHD in PWD would be to identify persons whose prognosis could be improved with an intervention (in this case, medical therapy for risk factors or coronary revascularization). In nearly all persons with diabetes, the results of screening will generally not change pharmaceutical medical therapy, since aggressive preventive measures, such as control of blood pressure and lipids, would already be indicated. Only in the case of aspirin administration, since there are real risks of gastrointestinal bleeding [110], one could argue that detection of CHD by screening might justify the therapy and might alter the risk/benefit ratio in favor of aspirin use
[111]. The same applies to intensification of antilipid therapy [112] in these patients.

In observational studies, there is a well-defined relationship between the extent and severity of myocardial ischaemia and the rate of occurrence of major CHD events [113]. Despite this observation, however, the role of interventional therapy in treating ischaemia (on top of GDOMT) is illdefined, and consequently, the role of screening procedures needs to be carefully examined.

Screening for CHD should be distinguished from the estimation of risk for CHD. By definition, both are performed in asymptomatic persons, and both aim to improve outcomes with interventions, if indicated. However, screening for $\mathrm{CHD}$ identifies existing disease, while estimating the risk of $\mathrm{CHD}$ does not directly identify existing disease but rather the likelihood of any future event related to CHD. The most important issue, however, is the effect of screening on hard outcomes (morbidity and mortality). Several prospective randomized trials have evaluated the impact of routine screening for subclinical CHD and the effect of therapy on outcomes of asymptomatic patients with type 2 diabetes. Taken altogether, these studies have shown no significant improvement in outcomes among patients who underwent screening $[44,114]$. Certainly, knowledge of presence of occult coronary atherosclerosis or significant $\mathrm{CHD}$ found by screening might lead to better compliance with medical therapy, but this has also not been definitively demonstrated [115].

An initial small study, conducted more than 10 years ago, had actually shown some benefit of screening for asymptomatic CHD in DM [116]. In that study, 141 asymptomatic persons with T2D, admitted to the hospital for uncontrolled hyperglycaemia, were randomized into a screening arm for CHD (with an exercise ECG test and dipyridamole stress echocardiography) or a control arm. If one screening test was abnormal, coronary angiography was performed, followed by revascularization (CABG or PCI) for stenoses $>50 \%$. After a mean follow-up of 53.5 months, the proportion of all cardiac events in the screened arm was significantly lower $(P=0.018)$, but with no difference in mortality.

In the largest study conducted to date (Detection of Ischemia in Asymptomatic Diabetics (DIAD study)) [117], 1123 type 2 diabetic patients without CHD symptoms at baseline were randomized to receive an adenosine rMPI, compared to no screening. In the screened group, the overall prevalence of silent myocardial ischaemia was $22 \%$. Of note, no guidance was given to the treating physicians regarding management of patients with ischaemia on rMPI. After a mean follow-up of 4.8 years, there was no significant difference in the primary endpoint (cardiac death or nonfatal MI) between the screening and no-screening groups $(2.7 \%$ versus $3.0 \%$, resp.). Of note, a small proportion of people underwent a coronary angiogram within 120 days after screening (only $4.4 \%$ of the screened population versus $0.5 \%$ of the unscreened, $P<0.01)$ and even less underwent revascularization ( $1.6 \%$ versus $0.6 \%$, resp., $P=0.03$ ).

In a similar, smaller study of 631 asymptomatic patients with T2D and at least two other CHD risk factors conducted in France, the DYNAMIT (Do You Need to Assess 
Myocardial Ischemia in Type-2 diabetes) investigators randomized patients to either screening with rMPI (with symptom-limited bicycle exercise or dipyridamole SPECT) or no screening [118]. In the screened group, the prevalence of silent myocardial ischaemia was $21.5 \%$, similar to the DIAD study. The study was discontinued prematurely because of difficulties in recruitment and a lower-than-expected event rate. After a mean follow-up of 3.5 years, there was no significant difference in the composite primary endpoint (death from all causes, nonfatal MI, nonfatal stroke, or heart failure requiring emergency intervention) between the screening and the nonscreening group (2.6\% versus $2.4 \%$ annually; adjusted HR: 1.0; 95\% CI: 0.59-1.71).

Equally negative results were found in a subsequent large study examining the benefit of screening for CHD in 900 diabetic patients (type 1 or 2) without prior CVD (FACTOR-64 trial) [119]. In contrast to the DIAD and DYNAMIT trials in which screening of asymptomatic patients with T2D was based on the identification of significant myocardial ischaemia using a functional stress test, the FACTOR-64 trial, conducted in the United States, evaluated the extent and severity of coronary atherosclerosis using an anatomic test (coronary computed tomography angiography (CCTA)). Also, contrary to the previous studies, it provided specific treatment guidance to the physicians, based on the CT results. Among patients randomized to CCTA screening, the prevalence of mild, moderate, and severe CHD was $31 \%, 46 \%$, and $12 \%$, respectively. After a mean follow-up of 4 years, there was no significant difference in the primary endpoint (composite of all-cause mortality, nonfatal MI, or unstable angina) following screening with CCTA $(6.2 \%$ versus $7.6 \%$ without screening; HR: 0.8; 95\% CI: 0.5-1.3).

Screening and revascularization of silent CHD in diabetic patients also failed to demonstrate a significant reduction in cardiac events and heart failure (HF) episodes in the Italian DADDY-D trial (Does coronary Atherosclerosis Deserve to be Diagnosed earlY in Diabetic patients?), where 520 diabetic patients without known CHD were randomly assigned to undergo screening for silent myocardial ischaemia (with exercise treadmill test) followed by revascularization if needed or to continue follow-up [120]. The reduction of cardiac death or nonfatal MI represented the primary aim; the secondary aim was the prevention of HF. After a mean follow-up of 3.6 years, there was no difference in cardiac events ( $\mathrm{HR}=0.85,95 \% \mathrm{CI}: 0.39-1.83, P=0.678$ ) or the occurrence of first HF episode (HR $=0.27,95 \%$ CI: $0.06-$ $1.31, P=0.083$ ).

A meta-analysis of all these 5 trials [114] corroborated the negative value of screening for asymptomatic CHD in diabetes. With a total number of 3315 asymptomatic diabetic patients included, and after 117 all-cause deaths and 100 cardiac events, it was shown that screening for CHD was not associated with a decrease in the risk for all-cause mortality (RR: 0.95 [95\% CI: 0.66 to 1.35]) or cardiac events (RR: 0.72 [95\% CI: 0.49 to 1.06]). This nonsignificant trend towards fewer cardiac events favouring the screening group seems to be driven by the study of Faglia et al. [116], which was the smallest and oldest study included in the analysis, with seemingly the poorest quality of patient treatment (patients had an unfavourable clinical profile, represented by the worst glycaemic control, the highest blood pressure, the greatest prevalence of smoking, and the lowest use of statins and aspirin in comparison with the other studies).

Complementary to the previous trials, the BARDOT trial (Basel Asymptomatic high-Risk Diabetics' Outcome Trial) evaluated the prognostic implications of medical versus invasive treatment in asymptomatic patients with T2D and abnormal screening test results (MPI-SPECT) [121]. In this study of 400 asymptomatic patients with T2D at high risk for CHD conducted in Switzerland and Germany, all patients underwent stress rMPI, which identified silent ischaemia in 88 participants (22\%), similar to the DIAD and DYNAMIT trials. These patients with abnormal stress rMPI were then randomized to medical therapy alone versus medical therapy plus invasive coronary revascularization (with PCI and stent placement or $\mathrm{CABG}$ ). The primary outcome was a combination of major adverse cardiac events (MACE: cardiac death, $\mathrm{MI}$, and symptom-driven revascularization) and worsening rMPI findings at 2-years follow-up. Patients with abnormal MPS randomized to medical versus invasive-medical strategies had similar hard event rates ((HR: 0.36; 95\% CI: 0.07 to $1.81 ; P=0.215)$, but more ischemic or new scar findings on repeat scintigraphy $(54.3 \%$ versus $15.8 \% ; P<0.001)$, implying that this kind of intervention could possibly ultimately reduce the risk of new downstream complications if broadly applied in the population [122]. The BARDOT trial results also slightly challenged the findings of the DIAD study (which included very low-risk patients and showed that rMPI screening is not effective at all in asymptomatic DM persons [117]), since in BARDOT, ischaemia testing in patients with diabetes at high coronary risk separated patients with CAD progression from those with a more benign course (in patients with normal MPS at baseline, MACE occurred in $2.9 \%$ and ischemia or new scar in $3.2 \%$, whereas patients with abnormal baseline MPS had more MACE [9.8\%] and ischemia or new scar [34.2\%] at 2 years follow-up), suggesting also that at least the subclinical progression to silent $\mathrm{CHD}$ may be reduced with invasive and medical treatment compared with medical management only.

Similar to these findings, the Impact of inDucible Ischemia by Stress MPS (IDIS) trial [123] showed that addition of MPS imaging data to a prediction model based on traditional risk factors and ECG stress test data significantly improved CHD risk classification in 822 high-risk diabetic patients. Overall, 301 patients were reclassified to a higher risk category, with an event rate of $28 \%$, and 26 to a lower risk category, with an event rate of $15 \%$ (net reclassification improvement (NRI): $0.25,95 \%$ confidence interval (CI): $0.15-0.34)$. Patients at the lowest baseline risk category ( $3 \%$ to $<5 \%$ risk) achieved a substantially higher NRI than the overall cohort (53\% were reclassified at higher risk and 25\% at lower risk, NRI: $0.42,95 \%$ CI: $0.07-0.76$ ), and therefore, patients in this category appear to be those who would benefit the most from a strategy that includes MPS data. Since in IDIS trial many of the participants were symptomatic or had a prior MI, the conclusions cannot be readily applied to a lower risk group of asymptomatic patients, with a 
substantially lower pretest risk of significant CAD [115]. However, in a subgroup analysis of the IDIS data [124], 436 consecutive asymptomatic diabetic patients who underwent stress-rest gated MPS were investigated and 27\% were found to have an abnormal MPS. At multivariable analysis, poststress left ventricular ejection fraction (LVEF) and stress MPS ischaemia were independent predictors of CHD death or MI (both $P<0.01$ ). NRI by adding MPS results to a model including pretest CHD likelihood was 0.25 (95\% CI: 0.06$0.44)$. Parametric survival analysis showed the highest probability of CAD death or MI and the major risk acceleration in time in patients with stress MPS ischaemia and poststress LVEF $<45 \%$. Together with other observational studies and meta-analyses $[125,126]$ of asymptomatic diabetic patient populations, these data show that silent ischaemia can be detected with screening and that such ischaemic findings are associated with an increased risk of cardiac events. Of course, such observational studies do not prove that outcomes are any better than optimal medical therapy, particularly in lower risk asymptomatic patients, which is the really most important issue [127].

\section{Efficacy of Interventions for Early-Detected CHD}

Although silent myocardial ischaemia has been associated with an increase in cardiac event rates compared to those without evidence of ischaemia in older studies [128-130], recent studies suggest that, in the contemporary GDOMT era, the presence of ischaemia is not related to the risk of death or MI in patients with SIHD [131-133] (in the older trials, the use of secondary prevention medications was substantially lower than that in the recent strategy trials [134]). And most importantly, studies that looked at the benefit of an invasive approach (PCI or CABG) together with optimal medical treatment of patients with stable, asymptomatic CHD compared to optimal medical treatment only (COURAGE and BARI-2D studies) have failed to show any benefit for the invasive approach $[135,136]$.

Specifically, in the COURAGE (Clinical Outcomes Using Revascularization and Aggressive Drug Evaluation) trial, 2287 patients with stable CHD were randomly assigned to either aggressive medical therapy alone or aggressive medical therapy plus PCI with bare-metal stenting [135]. Patients were required to have both objective evidence of ischaemia and significant disease in at least one coronary artery. Actually, $87 \%$ of participants were symptomatic, and only $34 \%$ had diabetes, so the study does not apply exclusively to silent $\mathrm{CHD}$ in diabetes. All patients received optimal medical therapy as indicated (ACE inhibitors or ARBs, statins, other lipid-lowering medications, aspirin, beta-blockers, calcium channel blockers, and nitrates). During a median follow-up of 4.6 years, there was no significant difference between the two treatment strategies for the primary end point of death from any cause and nonfatal MI (cumulative incidence approximately $19 \%$ in both groups; HR: 1.05 ; $95 \%$ CI: $0.87-1.27 ; P=0.62$ ). In addition, there was no significant difference in the rates of hospitalization for acute coronary syndrome (approximately 12\% in both groups; HR: 1.07;
95\% CI: 0.84-1.37; $P=0.56$ ). Patients in the PCI group, however, underwent significantly fewer subsequent revascularization procedures (21\% versus 33\%, HR: $0.60,95 \%$ CI: $0.51-0.71$ ). In a subsequent report comprising 1121 participants of the initial study at 15 years of follow-up (median 6.2 years), again no significant difference in the rate of death was found in the two groups ( $24 \%$ and $25 \%$, resp., adjusted HR: 1.03 ; 95\% CI: $0.83-1.21 ; P=0.76)$ [137].

Following the COURAGE trial, the results from the National Institutes of Health-National Heart, Lung and Blood Institute- (NIH-NHLBI-) sponsored BARI 2D (Bypass Angioplasty Revascularization Investigation 2 Diabetes) study were reported [136]. In that study, 2368 patients with T2D and stable ischaemic CHD were enrolled. Ischaemic CHD was defined as either a $\geq 50 \%$ stenosis of a major epicardial coronary artery associated with a positive stress test or $\geq 70 \%$ stenosis and classic angina. Prior to randomization to either revascularization (either PCI or CABG surgery) with intensive medical therapy (IMT) within four weeks or to IMT alone, patients were allocated in either the CABG or PCI stratum, as determined a priori by the responsible physician to be the most appropriate therapy for each patient. At 5 years, the primary end points of the rates of survival or freedom from major cardiovascular events (death, MI, or stroke) did not differ significantly between the revascularization group and the IMT alone group $(88.3 \%$ versus $87.8 \%$ and $77.2 \%$ versus $75.9 \%$, resp.). However, in subgroup analysis, the rate of freedom from major cardiovascular events was significantly higher in the CABG plus IMT stratum compared to the corresponding IMT stratum $(77.6 \%$ versus $69.5 \%)$, predominantly attributable to a reduction in nonfatal MI $(10.0 \%$ versus $17.6 \%$; $P=0.003)$ [138]. The rates for this end point were not significantly different between the PCI stratum and the corresponding IMT group $(77.0 \%$ versus $78.9 \%$, resp.). The lower event rate in the CABG plus IMT stratum was attributed to a preference of the treating physicians for CABG, rather than PCI, in patients with more extensive disease (including more triple-vessel and proximal left anterior descending coronary artery disease) [139]. Thus, this finding that $C A B G$ might be better than medical therapy alone for preventing major CVD events in diabetes must be interpreted with caution, as the allocation to PCI or CABG was not randomized.

Furthermore, studies using fractional flow reserve (FFR) to guide decision making have not yielded firm conclusions yet. FFR is a pressure wire-based index that is used during coronary angiography to assess the potential of a coronary stenosis to induce myocardial ischaemia [140]. The aim of the FAME-2 trial was to determine whether FFR-guided PCI with drug-eluting stents plus the best available medical therapy is superior to the best available medical therapy alone in reducing the rate of death, myocardial infarction, or unplanned hospitalization leading to urgent revascularization among 888 patients with stable CHD and FFR $<0.8$ [141]. There was no significant difference in mortality (HR: 0.33 , CI: $0.03-3.17, P=0.31$ ) or MI (HR: 1.05 , CI: $0.51-2.19, P=0.89$ ), partially because the trial's data safety monitoring board recommended enrollment to be stopped prematurely, after an interim analysis revealed a highly 
statistically significant decrease in unplanned hospitalization leading to urgent revascularization in the PCI arm. This drove a significant reduction in the composite primary endpoint (death, MI, or hospitalization for urgent revascularization) for FFR-guided PCI plus medical therapy as compared to medical therapy alone (HR: $0.32,95 \%$ CI: $0.19-0.53$, $P<0.0001)$. Thus, firm conclusions from this trial regarding the role of invasive procedures on hard end-points of CHD morbidity and mortality cannot be drawn.

Apart from that, meta-analyses of SIHD strategy trials do not support a difference in prognosis between routine revascularization and GDOMT only [142-144]. There is also some evidence that silent myocardial ischaemia may reverse over time with intensification of medical therapy [145].

Cost-effectiveness analyses also have not favoured interventional procedures in the randomized trials so far $[146,147]$.

\section{Recommendations of Major Scientific Organizations}

Based on the above-mentioned data, the American Diabetes Association does not recommend screening of asymptomatic diabetic patients with high atherosclerotic CVD risk [148], in part because these high-risk patients should already be receiving intensive medical therapy, an approach that provides similar benefit as invasive revascularization. They recommend investigation for $\mathrm{CHD}$ in the presence of any of the following: atypical cardiac symptoms (i.e., unexplained dyspnea, chest discomfort); signs or symptoms of associated vascular disease including carotid bruits, transient ischaemic attack, stroke, claudication, or peripheral arterial disease; or ECG abnormalities (e.g., Q waves) [108].

The European Society of Cardiology (ESC)/European Association for the Study of Diabetes (EASD) in their 2013 Guidelines on diabetes, prediabetes, and CVD concludes that in asymptomatic patients routine screening is controversial and still under debate [149]. In addition, they highlight the need for better definition of the characteristics of the patients who should be screened for CHD, stating that screening for silent myocardial ischaemia may be considered in selected high-risk patients with diabetes, such as patients with peripheral artery disease or high CAC score or with proteinuria.

While recommendations of other major scientific organizations vary regarding the optimal approach to screening for $\mathrm{CHD}$, no professional society guideline or consensus statement advocates for universal screening.

The United States Preventive Services Task Force (USPSTF) recommends against routine screening in adults at low risk for CHD events and also concludes that there is insufficient evidence to recommend for or against routine screening in adults at increased risk for CHD events [150].

The American College of Cardiology/American Heart Association (ACC/AHA) guidelines for exercise testing also issued a similar recommendation in 2002, that there is little evidence to support routine exercise testing in asymptomatic adults [151]. They further concluded that the weight of evidence favours evaluation of asymptomatic patients with diabetes who plan to begin a vigorous exercise programme and that exercise testing can be considered (although the weight of evidence is less clear) in the following patient populations: patients with multiple risk factors for $\mathrm{CHD}$ as a guide to risk reduction therapy, men over age 45 years and women over age 55 years who are presently sedentary and plan to start a vigorous exercise programme, and patients who are involved in occupations linked to public safety. Exercise testing can also be considered in patients who have undergone electron beam computed tomography (EBCT) and have a coronary calcium score above the 75th percentile.

The American College of Physicians (ACP) recommends against screening low-risk, asymptomatic adults with resting ECG, stress ECG, stress echocardiography, or stress myocardial perfusion imaging [152].

\section{Unresolved Issues and Future Studies}

Although the results from recent stable ischaemic heart disease randomized clinical trials have been negative as to whether the addition of coronary revascularization to GDOMT reduces death or major CVD events [135, 136], there are still some unresolved and confusing issues around this matter. For example, revascularization (PCI or CABG) compared with GDOMT was associated with reduced death and MI among 9676 propensity-matched "real-world" patients meeting COURAGE eligibility criteria [153]. Furthermore, in some observational studies, a strong relationship between the extent of ischaemia and subsequent death and/or MI and a possible benefit from revascularization has been observed. When at least moderate ischaemia $(>10 \%)$ was present, patients undergoing revascularization had fewer cardiac deaths than patients who were not revascularized [154]. Adding to the confusion, in the COURAGE nuclear substudy [155], among 105 patients with $>10 \%$ ischaemia who had follow-up scans 1 year later, those who received PCI were more likely to experience significant ischaemia reduction than GDOMT alone (78\% versus 52\%; $P=0.007$ ). Compared to those with persistent or worsening ischaemia, patients with ischaemia reduction by whatever means (i.e., PCI or GDOMT) had lower unadjusted risk for death or MI. However, a subsequent COURAGE analysis of outcomes by treatment group in 468 patients with at least moderate ischaemia on baseline rMPI showed no reduction in death or MI from the addition of PCI to GDOMT [156]. At the same time, though, crossover to PCI for progressive symptoms or ACS was required in $32 \%$ of GDOMT patients during a median 4.6-year follow-up in COURAGE and this reduces power to demonstrate differences.

Although the image of coronary arteries as kitchen pipes clogged with fat is simple, familiar, and evocative, it is also wrong [157]. The truth is that the angiogram is a poor discriminator of physiological lesion significance. Many lesions that appear angiographically severe may not produce ischaemia, and conversely, ischaemia may be present despite a benign angiographic lesion $[158,159]$. It may be that revascularization in SIHD may not be beneficial because not all anatomically obstructive coronary stenoses produce ischaemia, or because not all high-grade coronary stenoses result in cardiac death and/or MI, or conversely, because most cases 


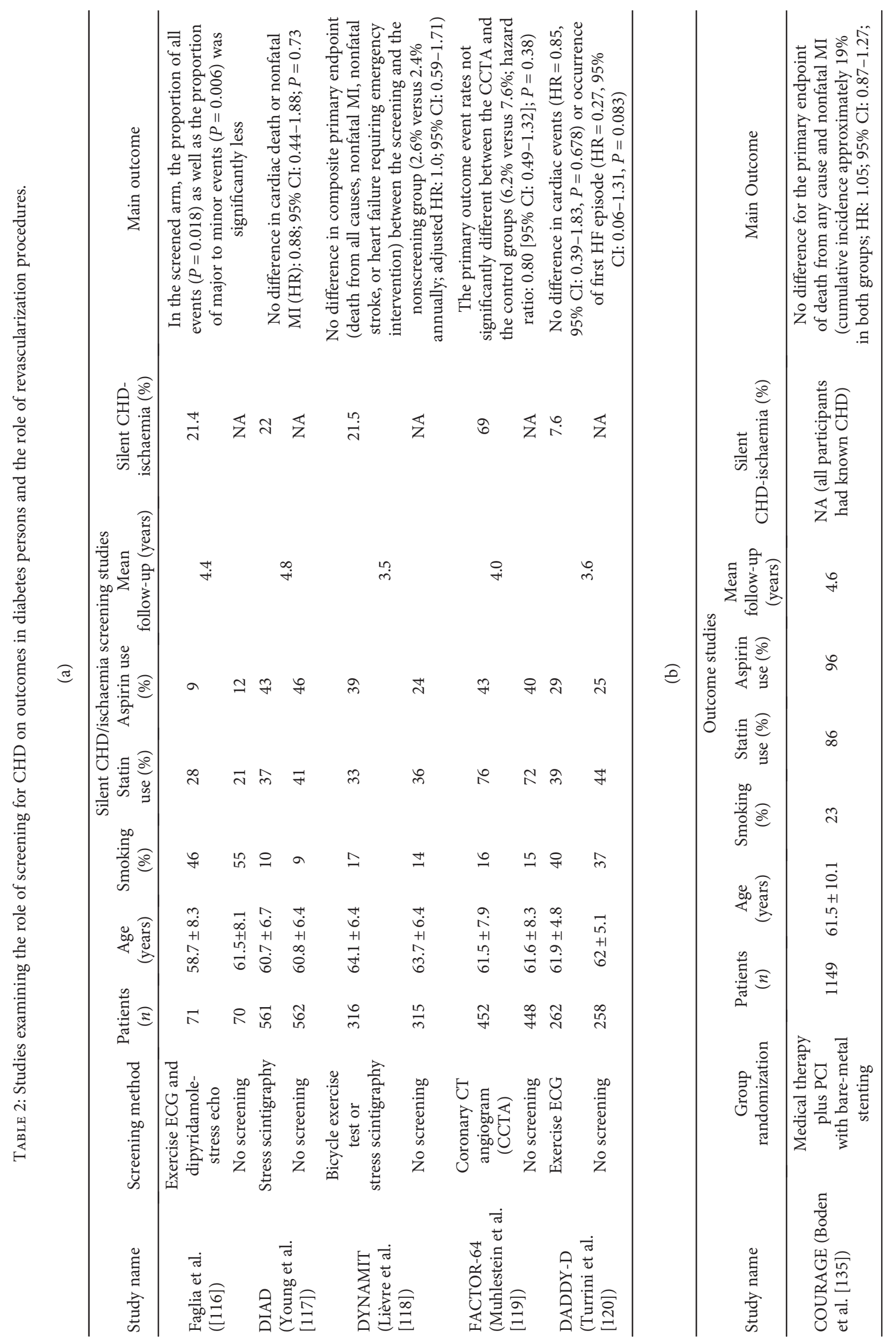




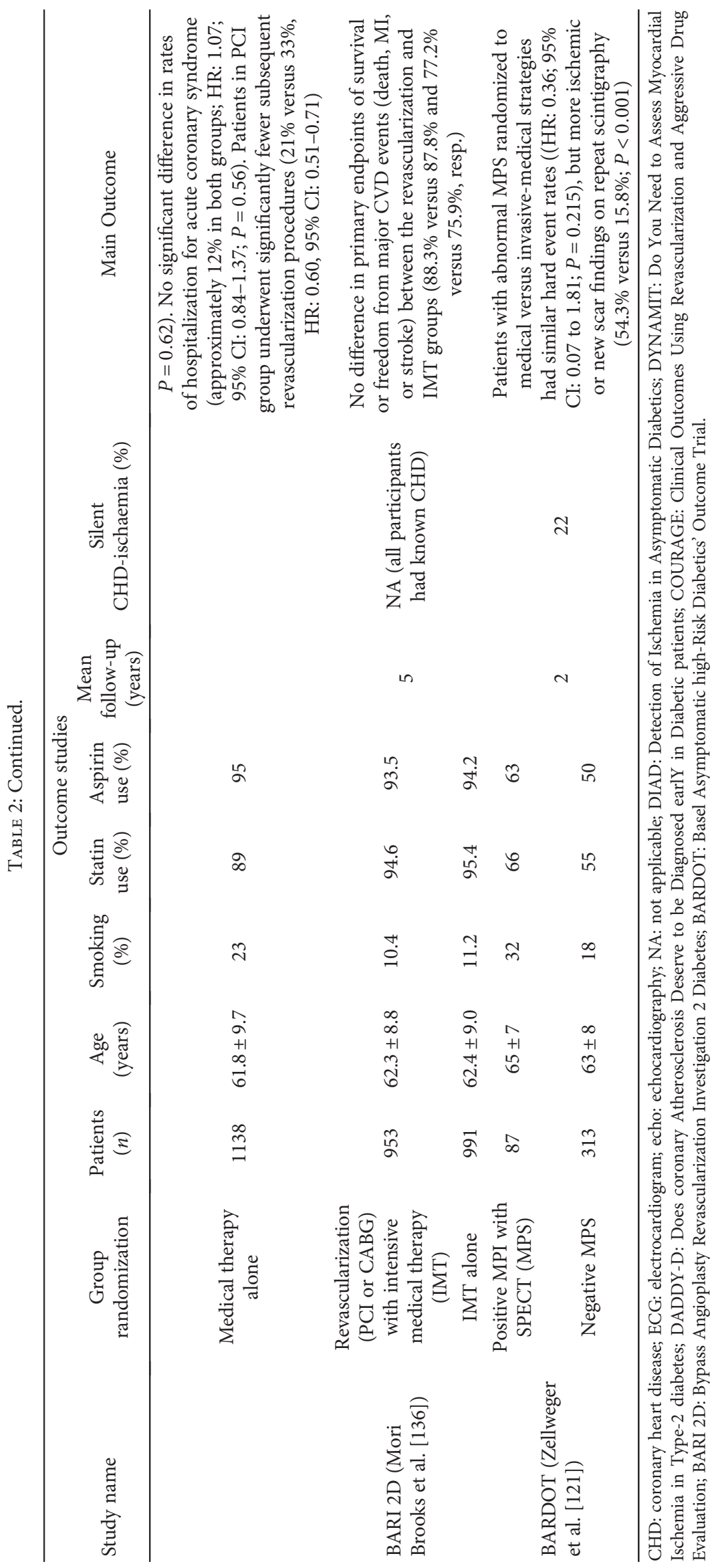


of cardiac death and/or MI arise from angiographically mild coronary lesions, which are not revascularized [160].

In addition, the studies mentioned were performed over several decades, and controlling for evolution in general medical practice is not possible. Indeed, many of these studies are of questionable relevance to contemporary practice today, given advances in GDOMT and revascularization techniques and devices. Of note, bare-metal stents (BMS) were used in most PCI versus GDOMT trials to date (including the COURAGE and BARI 2D studies). First-generation drug-eluting stents (DES) markedly reduce recurrent ischaemia compared with BMS [161], resulting in fewer hospitalizations for repeat revascularization [162]. Compared with BMS and first-generation DES, second-generation DES may further reduce death and MI and enhance event-free survival [163].

A potential explanation for failure of revascularization to reduce the incidence of death or MI in prior SIHD strategy trials is that lower risk patients were permitted into these trials, diluting the power to show a benefit from revascularization. Since it has been hypothesized that there is a level of ischaemia above which a revascularization strategy might result in benefit regarding cardiovascular events, this has mandated the performance of a specific study to determine the optimal approach to managing patients with SIHD, with moderate-to-severe ischaemia, and symptoms that can be controlled medically. The ongoing ISCHEMIA trial (International Study of Comparative Health Effectiveness With Medical and Invasive Approaches) (NCT01471522) is an NHLBIfunded international randomized controlled trial that began in 2012, with a primary aim of recruiting 8000 participants in order to determine whether an initial invasive strategy of cardiac catheterization and optimal revascularization (with PCI or CABG, as determined by the local heart team) plus GDOMT will reduce the primary composite endpoint of cardiovascular death or nonfatal MI in SIHD patients with moderate or severe ischaemia and medically controllable or absent symptoms, as compared with an initial conservative strategy of GDOMT alone, with catheterization reserved for failure of GDOMT. The major secondary endpoint is the angina-related quality of life. Other important secondary endpoints are health resource utilization, costs, and costeffectiveness. In addition to the main trial, 1000 additional patients with advanced chronic kidney disease (estimated glomerular filtration rate $<30 \mathrm{ml} / \mathrm{min}$ or on dialysis) will be randomized in a parallel NHLBI-funded ISCHEMIA-CKD ancillary substudy. Blinded CCTA is performed before randomization in participants with normal renal function to exclude those with significant left main artery disease and no obstructive CHD. This is in contrast to COURAGE and BARI 2D trials, where enrollment was not predicated on core laboratory confirmation of any significant degree of ischaemia. The rationale for including multiple imaging modalities is to enhance the generalizability of findings to the diverse modalities that are available to practicing clinicians caring for SIHD patients around the globe.

The ISCHEMIA study thus aims to address limitations of previous strategy trials by (1) enrolling patients before catheterization, so that anatomically high-risk patients are not excluded; (2) enrolling a higher-risk group with at least moderate ischaemia; (3) minimizing crossovers; (4) using contemporary DES and physiologically guided decision making (FFR) to achieve complete ischaemic (rather than anatomic) revascularization; and (5) being adequately powered to demonstrate whether routine revascularization reduces cardiovascular death or nonfatal MI in patients with SIHD and at least moderate ischaemia [45].

\section{Conclusions}

Diabetes is well known to significantly increase CVD risk, but cannot be considered a CHD equivalent, due to great heterogeneity of the patients. Nevertheless, life-time risk of CHD seems to be quite high in almost all people with the disease, which calls for individualized approach and evaluation for the presence and possible treatment of a great variety of other frequently coexisting risk factors that can increase this risk.

Apart from risk factor treatment, however, the value of invasive treatment of coronary atherosclerosis (except for the case of acute coronary syndromes) remains unsettled, because all prior randomized trials have limitations and are pointing towards equipoise [44, 45], and thus, routine screening for silent $\mathrm{CHD}$ in asymptomatic persons with DM is not currently recommended, as long as cardiovascular risk factors are treated (Table 2) [108]. It is hoped that the ongoing ISCHEMIA trial will give more definitive answers to the current uncertainties pertaining proper treatment of SIHD.

\section{Conflicts of Interest}

The authors declare that there is no conflict of interest regarding the publication of this article.

\section{References}

[1] International Diabetes Federation (IDF), "IDF Diabetes Atlas," 7th edition, 2015, https://www.idf.org/e-library/ epidemiology-research/diabetes-atlas/13-diabetes-atlas-seventhedition.html.

[2] T. Seuring, O. Archangelidi, and M. Suhrcke, "The economic costs of type 2 diabetes: a global systematic review," PharmacoEconomics, vol. 33, no. 8, pp. 811-831, 2015.

[3] UKPDS, "Intensive blood-glucose control with sulphonylureas or insulin compared with conventional treatment and risk of complications in patients with type 2 diabetes (UKPDS 33). UK Prospective Diabetes Study (UKPDS) Group," Lancet, vol. 352, no. 9131, pp. 837-853, 1998.

[4] R. R. Holman, S. K. Paul, M. A. Bethel, D. R. Matthews, and H. A. W. Neil, "10-year follow-up of intensive glucose control in type 2 diabetes," The New England Journal of Medicine, vol. 359, no. 15, pp. 1577-1589, 2008.

[5] K. Gu, C. C. Cowie, and M. I. Harris, "Mortality in adults with and without diabetes in a national cohort of the U.S. population, 1971-1993," Diabetes Care, vol. 21, no. 7, pp. 1138-1145, 1998.

[6] O. H. Franco, E. W. Steyerberg, F. B. Hu, J. Mackenbach, and W. Nusselder, "Associations of diabetes mellitus with total life expectancy and life expectancy with and without cardiovascular disease," Archives of Internal Medicine, vol. 167, no. 11, pp. 1145-1151, 2007. 
[7] S. Rao Kondapally Seshasai, S. Kaptoge, A. Thompson et al., "Diabetes mellitus, fasting glucose, and risk of cause-specific death," The New England Journal of Medicine, vol. 364, no. 9, pp. 829-841, 2011.

[8] M. I. Uusitupa, L. K. Niskanen, O. Siitonen, E. Voutilainen, and K. Pyörälä, "Ten-year cardiovascular mortality in relation to risk factors and abnormalities in lipoprotein composition in type 2 (non-insulin-dependent) diabetic and non-diabetic subjects," Diabetologia, vol. 36, no. 11, pp. 1175-1184, 1993.

[9] B. M. Leon and T. M. Maddox, "Diabetes and cardiovascular disease: epidemiology, biological mechanisms, treatment recommendations and future research," World Journal of Diabetes, vol. 6, no. 13, pp. 1246-1258, 2015.

[10] A. S. Matheus, L. R. Tannus, R. A. Cobas, C. C. Palma, C. A. Negrato, and M. B. Gomes, "Impact of diabetes on cardiovascular disease: an update," International Journal of Hypertension, vol. 2013, Article ID 653789, 15 pages, 2013.

[11] A. Nitenberg, P. Valensi, R. Sachs, M. Dali, E. Aptecar, and J. R. Attali, "Impairment of coronary vascular reserve and ACh-induced coronary vasodilation in diabetic patients with angiographically normal coronary arteries and normal left ventricular systolic function," Diabetes, vol. 42, no. 7, pp. 1017-1025, 1993.

[12] A. Nitenberg, F. Paycha, S. Ledoux, R. Sachs, J. R. Attali, and P. Valensi, "Coronary artery responses to physiological stimuli are improved by deferoxamine but not by L-arginine in non-insulin-dependent diabetic patients with angiographically normal coronary arteries and no other risk factors," Circulation, vol. 97, no. 8, pp. 736-743, 1998.

[13] J. P. J. Halcox, W. H. Schenke, G. Zalos et al., "Prognostic value of coronary vascular endothelial dysfunction," Circulation, vol. 106, no. 6, pp. 653-658, 2002.

[14] J. Shaw and T. Anderson, "Coronary endothelial dysfunction in non-obstructive coronary artery disease: risk, pathogenesis, diagnosis and therapy," Vascular Medicine, vol. 21, no. 2, pp. 146-155, 2016.

[15] S. Pasupathy, T. Air, R. P. Dreyer, R. Tavella, and J. F. Beltrame, "Systematic review of patients presenting with suspected myocardial infarction and nonobstructive coronary arteries," Circulation, vol. 131, no. 10, pp. 861-870, 2015.

[16] K. Najib, S. Boateng, S. Sangodkar et al., "Incidence and characteristics of patients presenting with acute myocardial infarction and non-obstructive coronary artery disease," Catheterization and Cardiovascular Interventions, vol. 86, Supplement S1, pp. S23-S27, 2015.

[17] G. O. von Mering, C. B. Arant, T. R. Wessel et al., "Abnormal coronary vasomotion as a prognostic indicator of cardiovascular events in women: results from the National Heart, Lung, and Blood Institute-Sponsored Women's Ischemia Syndrome Evaluation (WISE)," Circulation, vol. 109, no. 6, pp. 722-725, 2004.

[18] J. A. Beckman, M. A. Creager, and P. Libby, "Diabetes and atherosclerosis: epidemiology, pathophysiology, and management," JAMA, vol. 287, no. 19, pp. 2570-2581, 2002.

[19] J. Stamler, O. Vaccaro, J. D. Neaton, and D. Wentworth, "Diabetes, other risk factors, and 12-yr cardiovascular mortality for men screened in the multiple risk factor intervention trial," Diabetes Care, vol. 16, no. 2, pp. 434-444, 1993.

[20] A. Melidonis, V. Dimopoulos, E. Lempidakis et al., "Angiographic study of coronary artery disease in diabetic patients in comparison with nondiabetic patients," Angiology, vol. 50, no. 12, pp. 997-1006, 1999.
[21] S. Schiekofer, B. Balletshofer, M. Andrassy, A. Bierhaus, and P. P. Nawroth, "Endothelial dysfunction in diabetes mellitus," Seminars in Thrombosis and Hemostasis, vol. 26, no. 5, pp. 503-512, 2000.

[22] C. B. Granger, R. M. Califf, S. Young et al., "Outcome of patients with diabetes mellitus and acute myocardial infarction treated with thrombolytic agents. The Thrombolysis and Angioplasty in Myocardial Infarction (TAMI) Study Group," Journal of the American College of Cardiology, vol. 21, no. 4, pp. 920-925, 1993.

[23] P. R. Moreno, A. M. Murcia, I. F. Palacios et al., "Coronary composition and macrophage infiltration in atherectomy specimens from patients with diabetes mellitus," Circulation, vol. 102, no. 18, pp. 2180-2184, 2000.

[24] G. L. Booth, M. K. Kapral, K. Fung, and J. V. Tu, "Relation between age and cardiovascular disease in men and women with diabetes compared with non-diabetic people: a population-based retrospective cohort study," The Lancet, vol. 368, no. 9529, pp. 29-36, 2006.

[25] R. Huxley, F. Barzi, and M. Woodward, "Excess risk of fatal coronary heart disease associated with diabetes in men and women: meta-analysis of 37 prospective cohort studies," BMJ, vol. 332, no. 7533, pp. 73-78, 2006.

[26] A. De Lorenzo, R. S. L. Lima, A. G. Siqueira-Filho, and M. R. Pantoja, "Prevalence and prognostic value of perfusion defects detected by stress technetium-99m sestamibi myocardial perfusion single-photon emission computed tomography in asymptomatic patients with diabetes mellitus and no known coronary artery disease," The American Journal of Cardiology, vol. 90, no. 8, pp. 827-832, 2002.

[27] T. D. Miller, N. Rajagopalan, D. O. Hodge, R. L. Frye, and R. J. Gibbons, "Yield of stress single-photon emission computed tomography in asymptomatic patients with diabetes," American Heart Journal, vol. 147, no. 5, pp. 890-896, 2004.

[28] A. Langer, M. R. Freeman, R. G. Josse, and P. W. Armstrong, "Metaiodobenzylguanidine imaging in diabetes mellitus: assessment of cardiac sympathetic denervation and its relation to autonomic dysfunction and silent myocardial ischemia," Journal of the American College of Cardiology, vol. 25, no. 3, pp. 610-618, 1995.

[29] R. Scognamiglio, C. Negut, A. Ramondo, A. Tiengo, and A. Avogaro, "Detection of coronary artery disease in asymptomatic patients with type 2 diabetes mellitus," Journal of the American College of Cardiology, vol. 47, no. 1, pp. 65-71, 2006.

[30] T. Hammoud, J. F. Tanguay, and M. G. Bourassa, "Management of coronary artery disease: therapeutic options in patients with diabetes," Journal of the American College of Cardiology, vol. 36, no. 2, pp. 355-365, 2000.

[31] K. Franklin, R. J. Goldberg, F. Spencer et al., "Implications of diabetes in patients with acute coronary syndromes. The Global Registry of Acute Coronary Events," Archives of Internal Medicine, vol. 164, no. 13, pp. 1457-1463, 2004.

[32] S. M. Haffner, S. Lehto, T. Rönnemaa, K. Pyörälä, and M. Laakso, "Mortality from coronary heart disease in subjects with type 2 diabetes and in nondiabetic subjects with and without prior myocardial infarction," The New England Journal of Medicine, vol. 339, no. 4, pp. 229-234, 1998.

[33] M. R. Carnethon, M. L. Biggs, J. Barzilay et al., "Diabetes and coronary heart disease as risk factors for mortality in older adults," The American Journal of Medicine, vol. 123, no. 6, pp. 556.e1-556.e9, 2010. 
[34] K. Malmberg, S. Yusuf, H. C. Gerstein et al., "Impact of diabetes on long-term prognosis in patients with unstable angina and non-Q-wave myocardial infarction: results of the OASIS (Organization to Assess Strategies for Ischemic Syndromes) Registry," Circulation, vol. 102, no. 1019, pp. 1014-9, 2000.

[35] S. G. Wannamethee, A. G. Shaper, P. H. Whincup, L. Lennon, and N. Sattar, "Impact of diabetes on cardiovascular disease risk and all-cause mortality in older men: influence of age at onset, diabetes duration, and established and novel risk factors," Archives of Internal Medicine, vol. 171, no. 5, pp. 404-410, 2011.

[36] U. Bulugahapitiya, S. Siyambalapitiya, J. Sithole, and I. Idris, "Is diabetes a coronary risk equivalent? Systematic review and meta-analysis," Diabetic Medicine, vol. 26, no. 2, pp. 142-148, 2009.

[37] N. Sattar, "Revisiting the links between glycaemia, diabetes and cardiovascular disease," Diabetologia, vol. 56, no. 4, pp. 686-695, 2013.

[38] N. J. Stone, J. G. Robinson, A. H. Lichtenstein et al., “2013 ACC/AHA guideline on the treatment of blood cholesterol to reduce atherosclerotic cardiovascular risk in adults," Circulation, vol. 129, no. 25 Supplement 2, pp. S1-S45, 2014.

[39] M. F. Piepoli, A. W. Hoes, S. Agewall et al., "2016 European Guidelines on cardiovascular disease prevention in clinical practice: The Sixth Joint Task Force of the European Society of Cardiology and Other Societies on Cardiovascular Disease Prevention in Clinical Practice (constituted by representatives of 10 societies and by invited experts)," European Heart Journal, vol. 37, no. 29, pp. 2315-2381, 2016.

[40] S. M. Haffner, L. Mykkänen, A. Festa, J. P. Burke, and M. P. Stern, "Insulin-resistant prediabetic subjects have more atherogenic risk factors than insulin-sensitive prediabetic subjects: implications for preventing coronary heart disease during the prediabetic state," Circulation, vol. 101, no. 9, pp. 975-980, 2000.

[41] P. Gæde, H. Lund-Andersen, H.-H. Parving, and O. Pedersen, "Effect of a multifactorial intervention on mortality in type 2 diabetes," New England Journal of Medicine, vol. 358, no. 6, pp. 580-591, 2008.

[42] F. J. T. Wackers, L. H. Young, S. E. Inzucchi et al., "Detection of silent myocardial ischemia in asymptomatic diabetic subjects: the DIAD study," Diabetes Care, vol. 27, no. 8, pp. 1954-1961, 2004.

[43] P. T. O’Gara, F. G. Kushner, D. D. Ascheim et al., “2013 ACCF/AHA guideline for the management of ST-elevation myocardial infarction: executive summary: a report of the American College of Cardiology Foundation/American Heart Association Task Force on Practice Guidelines," Circulation, vol. 127, no. 4, pp. 529-555, 2013.

[44] L. M. Phillips, R. Hachamovitch, D. S. Berman et al., "Lessons learned from MPI and physiologic testing in randomized trials of stable ischemic heart disease: COURAGE, BARI 2D, FAME, and ISCHEMIA," Journal of Nuclear Cardiology, vol. 20, no. 6, pp. 969-975, 2013.

[45] G. W. Stone, J. S. Hochman, D. O. Williams et al., "Medical therapy with versus without revascularization in stable patients with moderate and severe ischemia: the case for community equipoise," Journal of the American College of Cardiology, vol. 67, no. 1, pp. 81-99, 2016.

[46] A. L. Cochrane and W. W. Holland, "Validation of screening procedures," British Medical Bulletin, vol. 27, no. 1, pp. 3-8, 1971.
[47] D. M. Nathan, P. A. Cleary, J.-Y. C. Backlund et al., "Intensive diabetes treatment and cardiovascular disease in patients with type 1 diabetes," The New England Journal of Medicine, vol. 353, no. 25, pp. 2643-2653, 2005.

[48] P. C. Deedwania and E. V. Carbajal, "Silent myocardial ischemia. A clinical perspective," Archives of Internal Medicine, vol. 151, no. 12, pp. 2373-2382, 1991.

[49] M. J. Budoff, P. Raggi, G. A. Beller et al., "Noninvasive cardiovascular risk assessment of the asymptomatic diabetic patient: The Imaging Council of the American College of Cardiology," JACC Cardiovascular Imaging, vol. 9, no. 2, pp. 176-192, 2016.

[50] S. D. Fihn, J. M. Gardin, J. Abrams et al., "2012 ACCF/AHA/ ACP/AATS/PCNA/SCAI/STS guideline for the diagnosis and management of patients with stable ischemic heart disease: a report of the American College of Cardiology Foundation/ American Heart Association task force on practice guidelines, and the American College of Physicians, American Association for Thoracic Surgery, Preventive Cardiovascular Nurses Association, Society for Cardiovascular Angiography and Interventions, and Society of Thoracic Surgeons," Circulation, vol. 126, no. 25, pp. e354-e471, 2012.

[51] C. Paillole, J. Ruiz, J. M. Juliard, H. Leblanc, R. Gourgon, and P. Passa, "Detection of coronary artery disease in diabetic patients," Diabetologia, vol. 38, no. 6, pp. 726-731, 1995.

[52] P. J. Scanlon, D. P. Faxon, A. M. Audet et al., “ACC/AHA guidelines for coronary angiography: executive summary and recommendations. A report of the American College of Cardiology/American Heart Association Task Force on Practice Guidelines (Committee on Coronary Angiography) developed in collaboration with the Society for Cardiac Angiography and Interventions," Circulation, vol. 99, no. 17, pp. 2345-2357, 1999.

[53] E. A. Caracciolo, B. R. Chaitman, S. A. Forman et al., "Diabetics with coronary disease have a prevalence of asymptomatic ischemia during exercise treadmill testing and ambulatory ischemia monitoring similar to that of nondiabetic patients. An ACIP database study. ACIP investigators. Asymptomatic cardiac ischemia pilot investigators," Circulation, vol. 93, no. 12, pp. 2097-2105, 1996.

[54] C. Kim, Y. S. Kwok, P. Heagerty, and R. Redberg, "Pharmacologic stress testing for coronary disease diagnosis: a meta-analysis," American Heart Journal, vol. 142, no. 6, pp. 934-944, 2001.

[55] S. Bacci, M. Villella, A. Villella et al., "Screening for silent myocardial ischaemia in type 2 diabetic patients with additional atherogenic risk factors: applicability and accuracy of the exercise stress test," European Journal of Endocrinology, vol. 147, no. 5, pp. 649-654, 2002.

[56] W. Acampa, V. Cantoni, R. Green et al., "Prognostic value of normal stress myocardial perfusion imaging in diabetic patients: a meta-analysis," Journal of Nuclear Cardiology, vol. 21, no. 5, pp. 893-902, 2014.

[57] R. Nakazato, D. S. Berman, E. Alexanderson, and P. Slomka, "Myocardial perfusion imaging with PET," Imaging in Medicine, vol. 5, no. 1, pp. 35-46, 2013.

[58] T. H. Marwick, C. Case, S. Sawada, C. Vasey, L. Short, and M. Lauer, "Use of stress echocardiography to predict mortality in patients with diabetes and known or suspected coronary artery disease," Diabetes Care, vol. 25, no. 6, pp. 1042-1048, 2002. 
[59] L. Cortigiani, R. Bigi, R. Sicari, P. Landi, F. Bovenzi, and E. Picano, "Prognostic value of pharmacological stress echocardiography in diabetic and nondiabetic patients with known or suspected coronary artery disease," Journal of the American College of Cardiology, vol. 47, no. 3, pp. 605-610, 2006.

[60] G. Di Leo, E. Fisci, F. Secchi et al., "Diagnostic accuracy of magnetic resonance angiography for detection of coronary artery disease: a systematic review and meta-analysis," European Radiology, vol. 26, no. 10, pp. 3706-3718, 2016.

[61] A. J. H. A. Scholte, J. D. Schuijf, A. V. Kharagjitsingh et al., "Prevalence of coronary artery disease and plaque morphology assessed by multi-slice computed tomography coronary angiography and calcium scoring in asymptomatic patients with type 2 diabetes," Heart, vol. 94, no. 3, pp. 290-295, 2008.

[62] I. Sarikaya, "Cardiac applications of PET," Nuclear Medicine Communications, vol. 36, no. 10, pp. 971-985, 2015.

[63] X. Kang, D. S. Berman, H. Lewin et al., "Comparative ability of myocardial perfusion single-photon emission computed tomography to detect coronary artery disease in patients with and without diabetes mellitus," American Heart Journal, vol. 137, no. 5, pp. 949-957, 1999.

[64] R. Hachamovitch, X. Kang, A. M. Amanullah et al., "Prognostic implications of myocardial perfusion single-photon emission computed tomography in the elderly," Circulation, vol. 120, no. 22, pp. 2197-2206, 2009.

[65] S. Giri, L. J. Shaw, D. R. Murthy et al., "Impact of diabetes on the risk stratification using stress single-photon emission computed tomography myocardial perfusion imaging in patients with symptoms suggestive of coronary artery disease," Circulation, vol. 105, no. 1, pp. 32-40, 2002.

[66] N. Rajagopalan, T. D. Miller, D. O. Hodge, R. L. Frye, and R. J. Gibbons, "Identifying high-risk asymptomatic diabetic patients who are candidates for screening stress singlephoton emission computed tomography imaging," Journal of the American College of Cardiology, vol. 45, no. 1, pp. 4349, 2005.

[67] S. Malhotra, R. Sharma, D. E. Kliner, W. P. Follansbee, and P. Soman, "Relationship between silent myocardial ischemia and coronary artery disease risk factors," Journal of Nuclear Cardiology, vol. 20, no. 5, pp. 731-738, 2013.

[68] D. V. Anand, E. Lim, D. Hopkins et al., "Risk stratification in uncomplicated type 2 diabetes: prospective evaluation of the combined use of coronary artery calcium imaging and selective myocardial perfusion scintigraphy," European Heart Journal, vol. 27, no. 6, pp. 713-721, 2006.

[69] J. Stolzenberg, "Dilatation of left ventricular cavity on stress thallium scan as an indicator of ischemic disease," Clinical Nuclear Medicine, vol. 5, no. 7, pp. 289-291, 1980.

[70] M. G. McLaughlin and P. G. Danias, "Transient ischemic dilation: a powerful diagnostic and prognostic finding of stress myocardial perfusion imaging," Journal of Nuclear Cardiology, vol. 9, no. 6, pp. 663-667, 2002.

[71] A. T. Weiss, D. S. Berman, A. S. Lew et al., "Transient ischemic dilation of the left ventricle on stress thallium-201 scintigraphy: a marker of severe and extensive coronary artery disease," Journal of the American College of Cardiology, vol. 9, no. 4, pp. 752-759, 1987.

[72] C. Valdiviezo, A. A. Motivala, R. Hachamovitch et al., "The significance of transient ischemic dilation in the setting of otherwise normal SPECT radionuclide myocardial perfusion images," Journal of Nuclear Cardiology, vol. 18, no. 2, pp. 220-229, 2011.

[73] W. T. Halligan, P. B. Morris, U. J. Schoepf et al., "Transient ischemic dilation of the left ventricle on SPECT: correlation with findings at coronary CT angiography," Journal of Nuclear Medicine, vol. 55, no. 6, pp. 917-922, 2014.

[74] M. Petretta, W. Acampa, S. Daniele, M. P. Petretta, M. Plaitano, and A. Cuocolo, "Transient ischemic dilation in patients with diabetes mellitus: prognostic value and effect on clinical outcome after coronary revascularization," Circulation Cardiovascular Imaging, vol. 6, no. 6, pp. 908-915, 2013.

[75] B. Fallahi, D. Beiki, A. Fard-Esfahani et al., "The additive value of transient left ventricular dilation using two-day dipyridamole $99 \mathrm{mTc}$-MIBI SPET for screening coronary artery disease in patients with otherwise normal myocardial perfusion: a comparison between diabetic and non-diabetic cases," Hellenic journal of nuclear medicine, vol. 13, no. 3, pp. 246-252, 2010.

[76] M. G. Sutton and N. Sharpe, "Left ventricular remodeling after myocardial infarction: pathophysiology and therapy," Circulation, vol. 101, no. 25, pp. 2981-2988, 2000.

[77] H. D. White, R. M. Norris, M. A. Brown, P. W. Brandt, R. M. Whitlock, and C. J. Wild, "Left ventricular endsystolic volume as the major determinant of survival after recovery from myocardial infarction," Circulation, vol. 76, no. 1, pp. 44-51, 1987.

[78] B. Knap, G. Juznic, A. F. Bren, G. Drzewiecki, and A. Noordergraaf, "Elongation as a new shape index for the left ventricle," The International Journal of Cardiovascular Imaging, vol. 18, no. 6, pp. 421-430, 2002.

[79] H. F. J. Mannaerts, J. A. van der Heide, O. Kamp, M. G. Stoel, J. Twisk, and C. A. Visser, "Early identification of left ventricular remodelling after myocardial infarction, assessed by transthoracic 3D echocardiography," European Heart Journal, vol. 25, no. 8, pp. 680-687, 2004.

[80] R. Bomb, S. Kumar, and A. Chockalingam, "Coronary artery disease detection - limitations of stress testing in left ventricular dysfunction," World Journal of Cardiology, vol. 9, no. 4, pp. 304-311, 2017.

[81] A. Abidov, P. J. Slomka, H. Nishina et al., "Left ventricular shape index assessed by gated stress myocardial perfusion SPECT: initial description of a new variable," Journal of Nuclear Cardiology, vol. 13, no. 5, pp. 652-659, 2006.

[82] G. Germano, H. Kiat, P. B. Kavanagh et al., "Automatic quantification of ejection fraction from gated myocardial perfusion SPECT," Journal of Nuclear Medicine, vol. 36, no. 11, pp. 2138-2147, 1995.

[83] A. Abidov, P. J. Slomka, H. Nishina et al., "Focal stress induced LV geometry changes independently predict presence of the angiographically significant CAD in patients undergoing myocardial perfusion SPECT," Journal of the American College of Cardiology, vol. 45, p. 15A, 2005.

[84] P. Slomka, D. S. Berman, E. Alexanderson, and G. Germano, "The role of PET quantification in cardiovascular imaging," Clinical and Translational Imaging, vol. 2, no. 4, pp. 343358, 2014

[85] V. L. Murthy, M. Naya, C. R. Foster et al., "Association between coronary vascular dysfunction and cardiac mortality in patients with and without diabetes mellitus," Circulation, vol. 126, no. 15, pp. 1858-1868, 2012. 
[86] B. A. Mc Ardle, T. F. Dowsley, R. A. deKemp, G. A. Wells, and R. S. Beanlands, "Does rubidium-82 PET have superior accuracy to SPECT perfusion imaging for the diagnosis of obstructive coronary disease?: a systematic review and meta-analysis," Journal of the American College of Cardiology, vol. 60 , no. 18, pp. 1828-1837, 2012.

[87] A. Elhendy, J. M. Tsutsui, E. L. O’Leary, F. Xie, A. C. McGrain, and T. R. Porter, "Noninvasive diagnosis of coronary artery disease in patients with diabetes by dobutamine stress real-time myocardial contrast perfusion imaging," Diabetes Care, vol. 28, no. 7, pp. 1662-7, 2005.

[88] S. S. Abdelmoneim, M. Bernier, A. Dhoble et al., “Assessment of myocardial perfusion during adenosine stress using real time three-dimensional and two-dimensional myocardial contrast echocardiography: comparison with single-photon emission computed tomography," Echocardiography, vol. 27, no. 4, pp. 421-429, 2010.

[89] E. B. Turkbey, J.-Y. C. Backlund, S. Genuth et al., "Myocardial structure, function, and scar in patients with type 1 diabetes mellitus," Circulation, vol. 124, no. 16, pp. 1737-1746, 2011.

[90] Y. Ichikawa, H. Sakuma, N. Suzawa et al., "Late gadoliniumenhanced magnetic resonance imaging in acute and chronic myocardial infarction: improved prediction of regional myocardial contraction in the chronic state by measuring thickness of nonenhanced myocardium," Journal of the American College of Cardiology, vol. 45, no. 6, pp. 901-909, 2005.

[91] J. A. Rumberger, D. B. Simons, L. A. Fitzpatrick, P. F. Sheedy, and R. S. Schwartz, "Coronary artery calcium area by electron-beam computed tomography and coronary atherosclerotic plaque area. A histopathologic correlative study," Circulation, vol. 92, no. 8, pp. 2157-2162, 1995.

[92] M. J. Budoff, S. Möhlenkamp, R. McClelland et al., "A comparison of outcomes with coronary artery calcium scanning in unselected populations: the Multi-Ethnic Study of Atherosclerosis (MESA) and Heinz Nixdorf RECALL study (HNR)," Journal of Cardiovascular Computed Tomography, vol. 7, no. 3, pp. 182-191, 2013.

[93] N. D. Wong, M. G. Sciammarella, D. Polk et al., "The metabolic syndrome, diabetes, and subclinical atherosclerosis assessed by coronary calcium," Journal of the American College of Cardiology, vol. 41, no. 9, pp. 1547-1553, 2003.

[94] S. Schurgin, S. Rich, and T. Mazzone, "Increased prevalence of significant coronary artery calcification in patients with diabetes," Diabetes Care, vol. 24, no. 2, pp. 335-338, 2001.

[95] E. Khaleeli, S. R. Peters, K. Bobrowsky, R. J. Oudiz, J. Y. Ko, and M. J. Budoff, "Diabetes and the associated incidence of subclinical atherosclerosis and coronary artery disease: Implications for management," American Heart Journal, vol. 141, no. 4, pp. 637-644, 2001.

[96] C. H. Mielke, J. P. Shields, and L. D. Broemeling, "Coronary artery calcium, coronary artery disease, and diabetes," Diabetes Research and Clinical Practice, vol. 53, no. 1, pp. 55-61, 2001.

[97] Z. X. He, T. D. Hedrick, C. M. Pratt et al., "Severity of coronary artery calcification by electron beam computed tomography predicts silent myocardial ischemia," Circulation, vol. 101, no. 3, pp. 244-251, 2000.

[98] N. D. Wong, A. Rozanski, H. Gransar et al., "Metabolic syndrome and diabetes are associated with an increased likelihood of inducible myocardial ischemia among patients with subclinical atherosclerosis," Diabetes Care, vol. 28, no. 6, pp. 1445-1450, 2005.
[99] J. Yeboah, R. Erbel, J. C. Delaney et al., "Development of a new diabetes risk prediction tool for incident coronary heart disease events: The Multi-Ethnic Study of Atherosclerosis and the Heinz Nixdorf Recall Study," Atherosclerosis, vol. 236, no. 2, pp. 411-417, 2014.

[100] G.-M. Park, J.-H. Lee, S.-W. Lee et al., "Comparison of coronary computed tomographic angiographic findings in asymptomatic subjects with versus without diabetes mellitus," The American Journal of Cardiology, vol. 116, no. 3, pp. 372-378, 2015.

[101] S. Kiramijyan, N. Ahmadi, H. Isma'eel et al., "Impact of coronary artery calcium progression and statin therapy on clinical outcome in subjects with and without diabetes mellitus," The American Journal of Cardiology, vol. 111, no. 3, pp. 356361, 2013.

[102] P. Raggi, L. J. Shaw, D. S. Berman, and T. Q. Callister, "Prognostic value of coronary artery calcium screening in subjects with and without diabetes," Journal of the American College of Cardiology, vol. 43, no. 9, pp. 1663-9, 2004.

[103] I. Gottlieb, J. M. Miller, A. Arbab-Zadeh et al., "The absence of coronary calcification does not exclude obstructive coronary artery disease or the need for revascularization in patients referred for conventional coronary angiography," Journal of the American College of Cardiology, vol. 55, no. 7, pp. 627-634, 2010.

[104] D. C. Goff, D. M. Lloyd-Jones, G. Bennett et al., "2013 ACC/ AHA guideline on the assessment of cardiovascular risk: a report of the American College of Cardiology/American Heart Association Task Force on Practice Guidelines," Journal of the American College of Cardiology, vol. 63, no. 25, Part B, pp. 2935-2959, 2014.

[105] P. Gueret, J.-F. Deux, L. Bonello et al., "Diagnostic performance of computed tomography coronary angiography (from the Prospective National Multicenter Multivendor EVASCAN Study)," The American Journal of Cardiology, vol. 111, no. 4, pp. 471-478, 2013.

[106] J. D. Schuijf, J. J. Bax, L. J. Shaw et al., "Meta-analysis of comparative diagnostic performance of magnetic resonance imaging and multislice computed tomography for noninvasive coronary angiography," American Heart Journal, vol. 151, no. 2, pp. 404-411, 2006.

[107] M. J. Wolk, S. R. Bailey, J. U. Doherty et al., “ACCF/AHA/ ASE/ASNC/HFSA/HRS/SCAI/SCCT/SCMR/STS 2013 multimodality appropriate use criteria for the detection and risk assessment of stable ischemic heart disease: a report of the American College of Cardiology Foundation Appropriate Use Criteria Task Force, American Heart Association, American Society of Echocardiography, American Society of Nuclear Cardiology, Heart Failure Society of America, Heart Rhythm Society, Society for Cardiovascular Angiography and Interventions, Society of Cardiovascular Computed Tomography, Society for Cardiovascular Magnetic Resonance, and Society of Thoracic Surgeons," Journal of the American College of Cardiology, vol. 63, no. 4, pp. 380-406, 2014.

[108] American Diabetes Association, "9. Cardiovascular disease and risk management," Diabetes Care, vol. 40, Supplement 1, pp. S75-S87, 2017.

[109] A. Berrington de González, M. Mahesh, K.-P. Kim et al., "Projected cancer risks from computed tomographic scans performed in the United States in 2007," Archives of Internal Medicine, vol. 169, no. 22, pp. 2071-2077, 2009. 
[110] M. Pignone, M. J. Alberts, J. A. Colwell et al., "Aspirin for primary prevention of cardiovascular events in people with diabetes," Journal of the American College of Cardiology, vol. 55, no. 25, pp. 2878-2886, 2010.

[111] M. G. Silverman, M. J. Blaha, M. J. Budoff et al., "Potential implications of coronary artery calcium testing for guiding aspirin use among asymptomatic individuals with diabetes," Diabetes Care, vol. 35, no. 3, pp. 624-626, 2012.

[112] A. L. Catapano, I. Graham, G. De Backer et al., "2016 ESC/ EAS guidelines for the management of dyslipidaemias," European Heart Journal, vol. 37, no. 39, pp. 2999-3058, 2016.

[113] R. Hachamovitch, D. S. Berman, L. J. Shaw et al., "Incremental prognostic value of myocardial perfusion single photon emission computed tomography for the prediction of cardiac death: differential stratification for risk of cardiac death and myocardial infarction," Circulation, vol. 97, no. 6, pp. 535543, 1998.

[114] D. V. Rados, L. C. Pinto, C. B. Leitão, and J. L. Gross, "Screening for coronary artery disease in patients with type 2 diabetes: a meta-analysis and trial sequential analysis," BMJ Open, vol. 7, no. 5, article e015089, 2017.

[115] G. A. Beller and J. M. Bourque, "Screening asymptomatic patients with type 2 diabetes: the debates persist," Journal of Nuclear Cardiology, vol. 22, no. 1236, pp. 1233-6, 2015.

[116] E. Faglia, M. Manuela, Q. Antonella et al., "Risk reduction of cardiac events by screening of unknown asymptomatic coronary artery disease in subjects with type 2 diabetes mellitus at high cardiovascular risk: an open-label randomized pilot study," American Heart Journal, vol. 149, no. 2, pp. e1-e6, 2005.

[117] I. H. Young, F. J. T. Wackers, D. A. Chyun et al., "Cardiac outcomes after screening for asymptomatic coronary artery disease in patients with type 2 diabetes: the DIAD study: a randomized controlled trial," JAMA, vol. 301, no. 15, pp. 1547-1555, 2009.

[118] I. M. Lièvre, P. Moulin, C. Thivolet et al., "Detection of silent myocardial ischemia in asymptomatic patients with diabetes: results of a randomized trial and meta-analysis assessing the effectiveness of systematic screening," Trials, vol. 12, no. 1, p. 23, 2011.

[119] J. B. Muhlestein, D. L. Lappé, J. A. C. Lima et al., "Effect of screening for coronary artery disease using CT angiography on mortality and cardiac events in high-risk patients with diabetes. The FACTOR-64 randomized clinical trial," JAMA, vol. 312, no. 21, pp. 2234-2243, 2014.

[120] F. Turrini, S. Scarlini, C. Mannucci et al., "Does coronary atherosclerosis deserve to be diagnosed early in diabetic patients? The DADDY-D trial. Screening diabetic patients for unknown coronary disease," European Journal of Internal Medicine, vol. 26, no. 6, pp. 407-413, 2015.

[121] M. J. Zellweger, M. Maraun, H. H. Osterhues et al., "Progression to overt or silent CAD in asymptomatic patients with diabetes mellitus at high coronary risk: main findings of the prospective multicenter BARDOT trial with a pilot randomized treatment substudy," JACC: Cardiovascular Imaging, vol. 7, no. 10, pp. 1001-10, 2014.

[122] P. A. McCullough, P. Fazel, and J. W. Choi, "Screening, diagnosis, and management of CAD in asymptomatic diabetic patients," JACC Cardiovascular Imaging, vol. 7, no. 10, pp. 1011-1012, 2014.

[123] W. Acampa, M. Petretta, L. Evangelista et al., "Myocardial perfusion imaging and risk classification for coronary heart disease in diabetic patients. The IDIS study: a prospective, multicentre trial," European Journal of Nuclear Medicine and Molecular Imaging, vol. 39, no. 3, pp. 387-395, 2012.

[124] W. Acampa, M. Petretta, S. Daniele et al., "Incremental prognostic value of stress myocardial perfusion imaging in asymptomatic diabetic patients," Atherosclerosis, vol. 227, no. 2, pp. 307-312, 2013.

[125] L. Zhang, H. Li, S. Zhang, L. M. Jaacks, Y. Li, and L. Ji, “Silent myocardial ischemia detected by single photon emission computed tomography (SPECT) and risk of cardiac events among asymptomatic patients with type 2 diabetes: a metaanalysis of prospective studies," Journal of diabetes and its complications, vol. 28, no. 3, pp. 413-418, 2014.

[126] M. Petretta and A. Cuocolo, "Screening asymptomatic patients with type 2 diabetes is recommended: Pro," Journal of Nuclear Cardiology, vol. 22, no. 6, pp. 1225-1228, 2015.

[127] R. J. Gibbons, "Screening asymptomatic patients with type 2 diabetes is recommended-Con," Journal of Nuclear Cardiology, vol. 22, no. 6, pp. 1229-1232, 2015.

[128] C. J. Pepine, B. Sharaf, T. C. Andrews et al., "Relation between clinical, angiographic and ischemic findings at baseline and ischemia-related adverse outcomes at 1 year in the Asymptomatic Cardiac Ischemia Pilot study. ACIP Study Group," Journal of the American College of Cardiology, vol. 29, no. 7, pp. 1483-1489, 1997.

[129] G. Vanzetto, O. Ormezzano, D. Fagret, M. Comet, B. Denis, and J. Machecourt, "Long-term additive prognostic value of thallium-201 myocardial perfusion imaging over clinical and exercise stress test in low to intermediate risk patients," Circulation, vol. 100, no. 14, pp. 1521-1527, 1999.

[130] P. C. Deedwania, "Silent ischemia predicts poor outcome in high-risk healthy men," Journal of the American College of Cardiology, vol. 38, no. 1, pp. 80-83, 2001.

[131] L. J. Shaw, M. D. Cerqueira, M. M. Brooks et al., "Impact of left ventricular function and the extent of ischemia and scar by stress myocardial perfusion imaging on prognosis and therapeutic risk reduction in diabetic patients with coronary artery disease: results from the Bypass Angioplasty Revascularization Investigation 2 Diabetes (BARI 2D) trial," Journal of Nuclear Cardiology, vol. 19, no. 4, pp. 658-669, 2012.

[132] N. Aldweib, K. Negishi, R. Hachamovitch, W. A. Jaber, S. Seicean, and T. H. Marwick, "Impact of repeat myocardial revascularization on outcome in patients with silent ischemia after previous revascularization," Journal of the American College of Cardiology, vol. 61, no. 15, pp. 1616-1623, 2013.

[133] G. B. J. Mancini, P. M. Hartigan, L. J. Shaw et al., "Predicting outcome in the COURAGE trial (clinical outcomes utilizing revascularization and aggressive drug evaluation): coronary anatomy versus ischemia," JACC: Cardiovascular Interventions, vol. 7, no. 2, pp. 195-201, 2014.

[134] W. Hueb, P. R. Soares, B. J. Gersh et al., "The medicine, angioplasty, or surgery study (MASS-II): a randomized, controlled clinical trial of three therapeutic strategies for multivessel coronary artery disease: one-year results," Journal of the American College of Cardiology, vol. 43, no. 10, pp. 1743-1751, 2004.

[135] W. E. Boden, R. A. O'Rourke, K. K. Teo et al., "Optimal medical therapy with or without pci for stable coronary disease," The New England Journal of Medicine, vol. 356, no. 15, pp. 1503-1516, 2007.

[136] R. Mori Brooks, R. M. Hardison, S. F. Kelsey et al., “A randomized trial of therapies for type 2 diabetes and coronary 
artery disease," The New England Journal of Medicine, vol. 360, no. 24, pp. 2503-2515, 2009.

[137] S. P. Sedlis, P. M. Hartigan, K. K. Teo et al., "Effect of PCI on long-term survival in patients with stable ischemic heart disease," The New England Journal of Medicine, vol. 373, no. 20, pp. 1937-1946, 2015.

[138] B. R. Chaitman, R. M. Hardison, D. Adler et al., "The bypass angioplasty revascularization investigation 2 diabetes randomized trial of different treatment strategies in type 2 diabetes mellitus with stable ischemic heart disease: impact of treatment strategy on cardiac mortality and myocardial infarction," Circulation, vol. 120, no. 25, pp. 2529-2540, 2009.

[139] M. M. Brooks, B. R. Chaitman, R. W. Nesto et al., "Clinical and angiographic risk stratification and differential impact on treatment outcomes in the bypass angioplasty revascularization investigation 2 diabetes (BARI 2D) trial," Circulation, vol. 126, no. 17, pp. 2115-2124, 2012.

[140] N. H. J. Pijls, B. de Bruyne, K. Peels et al., "Measurement of fractional flow reserve to assess the functional severity of coronary-artery stenoses," The New England Journal of Medicine, vol. 334, no. 26, pp. 1703-1708, 1996.

[141] B. De Bruyne, N. H. J. Pijls, B. Kalesan et al., "Fractional flow reserve-guided PCI versus medical therapy in stable coronary disease," The New England journal of Medicine, vol. 367, no. 11, pp. 991-1001, 2012.

[142] H. C. Wijeysundera and D. T. Ko, "Does percutaneous coronary intervention reduce mortality in patients with stable chronic angina," Circulation: Cardiovascular Quality and Outcomes, vol. 2, no. 2, pp. 123-126, 2009.

[143] T. A. Trikalinos, A. A. Alsheikh-Ali, A. Tatsioni, B. K. Nallamothu, D. M. Kent, and A. Kastrati, "Percutaneous coronary interventions for non-acute coronary artery disease: a quantitative 20-year synopsis and a network meta-analysis," The Lancet, vol. 373, no. 9667, pp. 911-918, 2009.

[144] K. Stergiopoulos, W. E. Boden, P. Hartigan et al., "Percutaneous coronary intervention outcomes in patients with stable obstructive coronary artery disease and myocardial ischemia: a collaborative meta-analysis of contemporary randomized clinical trials," JAMA Internal Medicine, vol. 174, no. 2, pp. 232-240, 2014.

[145] F. J. T. Wackers, D. A. Chyun, L. H. Young et al., "Resolution of asymptomatic myocardial ischemia in patients with type 2 diabetes in the detection of ischemia in asymptomatic diabetics (DIAD) study," Diabetes care, vol. 30, no. 11, pp. 2892-2898, 2007.

[146] W. S. Weintraub, W. E. Boden, Z. Zhang et al., "Cost-effectiveness of percutaneous coronary intervention in optimally treated stable coronary patients. clinical perspective," Circulation: Cardiovascular Quality and Outcomes, vol. 1, no. 1, pp. 12-20, 2008.

[147] M. A. Hlatky, D. B. Boothroyd, K. A. Melsop et al., "Economic outcomes of treatment strategies for type 2 diabetes mellitus and coronary artery disease in the bypass angioplasty revascularization investigation 2 diabetes trial," Circulation, vol. 120, no. 25, pp. 2550-2558, 2009.

[148] J. J. Bax, L. H. Young, R. L. Frye, R. O. Bonow, H. O. Steinberg, and E. J. Barrett, "Screening for coronary artery disease in patients with diabetes," Diabetes Care, vol. 30, no. 10, pp. 2729-2736, 2007.

[149] L. Rydén, P. J. Grant, S. D. Anker et al., "ESC guidelines on diabetes, pre-diabetes, and cardiovascular diseases developed in collaboration with the EASD: the task force on diabetes, pre-diabetes, and cardiovascular diseases of the European Society of Cardiology (ESC) and developed in collaboration with the European Association for the Study of Diabetes (EASD)," European Heart Journal, vol. 34, no. 39, pp. 30353087, 2013.

[150] V. A. Moyer and U.S. Preventive Services Task Force, "Screening for coronary heart disease with electrocardiography: U.S. Preventive Services Task Force recommendation statement," Annals of Internal Medicine, vol. 157, no. 7, pp. 512-518, 2012.

[151] R. J. Gibbons, G. J. Balady, J. T. Bricker et al., “ACC/AHA 2002 guideline update for exercise testing: summary article. A report of the American College of Cardiology/American Heart Association Task Force on practice guidelines (committee to update the 1997 exercise testing guidelines)," Journal of the American College of Cardiology, vol. 40, no. 8, pp. 1531-1540, 2002.

[152] R. Chou and High Value Care Task Force of the American College of Physicians, "Cardiac screening with electrocardiography, stress echocardiography, or myocardial perfusion imaging: advice for high-value care from the American College of Physicians," Annals of Internal Medicine, vol. 162, no. 6, pp. 438-447, 2015.

[153] H. C. Wijeysundera, M. C. Bennell, F. Qiu et al., "Comparative-effectiveness of revascularization versus routine medical therapy for stable ischemic heart disease: a populationbased study," Journal of General Internal Medicine, vol. 29, no. 7, pp. 1031-1039, 2014.

[154] R. Hachamovitch, S. W. Hayes, J. D. Friedman, I. Cohen, and D. S. Berman, "Comparison of the short-term survival benefit associated with revascularization compared with medical therapy in patients with no prior coronary artery disease undergoing stress myocardial perfusion single photon emission computed tomography," Circulation, vol. 107, no. 23, pp. 2900-2907, 2003.

[155] L. J. Shaw, D. S. Berman, D. J. Maron et al., "Optimal medical therapy with or without percutaneous coronary intervention to reduce ischemic burden: results from the clinical outcomes utilizing revascularization and aggressive drug evaluation (COURAGE) trial nuclear substudy," Circulation, vol. 117, no. 10, pp. 1283-1291, 2008.

[156] L. J. Shaw, W. S. Weintraub, D. J. Maron et al., "Baseline stress myocardial perfusion imaging results and outcomes in patients with stable ischemic heart disease randomized to optimal medical therapy with or without percutaneous coronary intervention," American Heart Journal, vol. 164, no. 2, pp. 243-250, 2012.

[157] M. B. Rothberg, "Coronary artery disease as clogged pipes: a misconceptual model," Circulation: Cardiovascular Quality and Outcomes, vol. 6, no. 1, pp. 129-132, 2013.

[158] G. W. Stone, A. Maehara, A. J. Lansky et al., "A prospective natural-history study of coronary atherosclerosis," The New England Journal of Medicine, vol. 364, no. 3, pp. 226-235, 2011.

[159] S.-J. Park, S.-J. Kang, J.-M. Ahn et al., "Visual-functional mismatch between coronary angiography and fractional flow reserve," JACC: Cardiovascular Interventions, vol. 5, no. 10, pp. 1029-1036, 2012.

[160] D. G. Katritsis, J. Pantos, and E. Efstathopoulos, "Hemodynamic factors and atheromatic plaque rupture in the coronary arteries: from vulnerable plaque to vulnerable coronary 
segment," Coronary Artery Disease, vol. 18, no. 3, pp. 229237, 2007.

[161] M. J. Zellweger, C. Kaiser, H. P. Brunner-La Rocca et al., "Value and limitations of target-vessel ischemia in predicting late clinical events after drug-eluting stent implantation," Journal of Nuclear Medicine, vol. 49, no. 4, pp. 550-556, 2008.

[162] A. J. Kirtane, A. Gupta, S. Iyengar et al., "Safety and efficacy of drug-eluting and bare metal stents," Circulation, vol. 119, no. 25, pp. 3198-3206, 2009.

[163] T. Palmerini, G. Biondi-Zoccai, D. Della Riva et al., "Clinical outcomes with bioabsorbable polymer-versus durable polymer-based drug-eluting and bare-metal stents: evidence from a comprehensive network meta-analysis," Journal of the American College of Cardiology, vol. 63, no. 4, pp. 299307, 2014. 


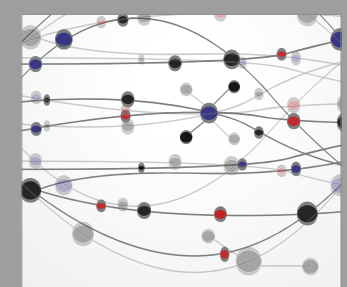

The Scientific World Journal
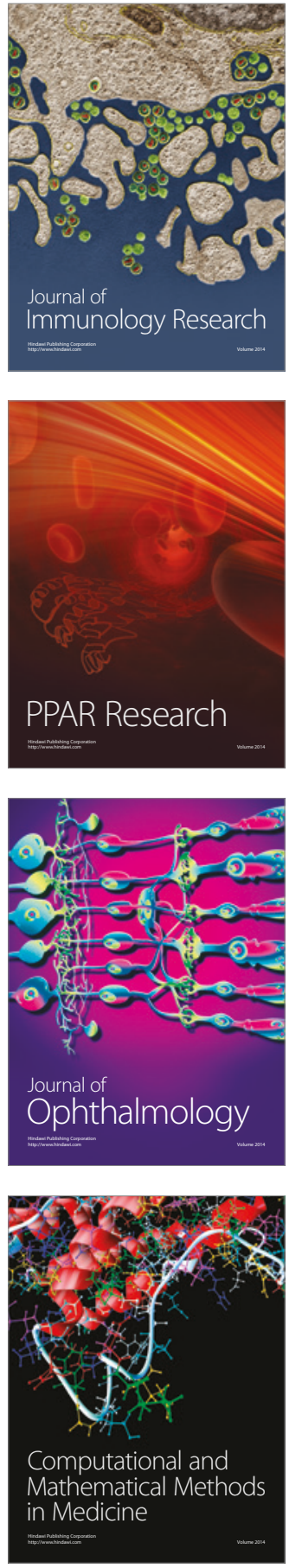

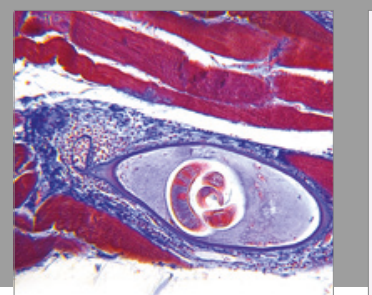

Gastroenterology Research and Practice
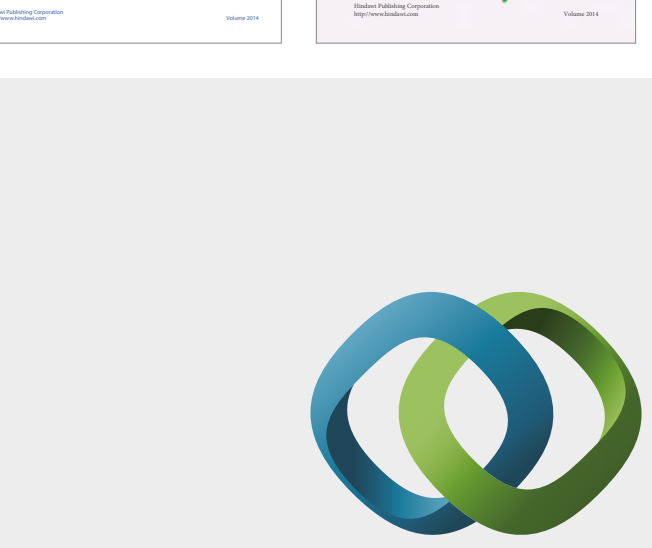

\section{Hindawi}

Submit your manuscripts at

https://www.hindawi.com
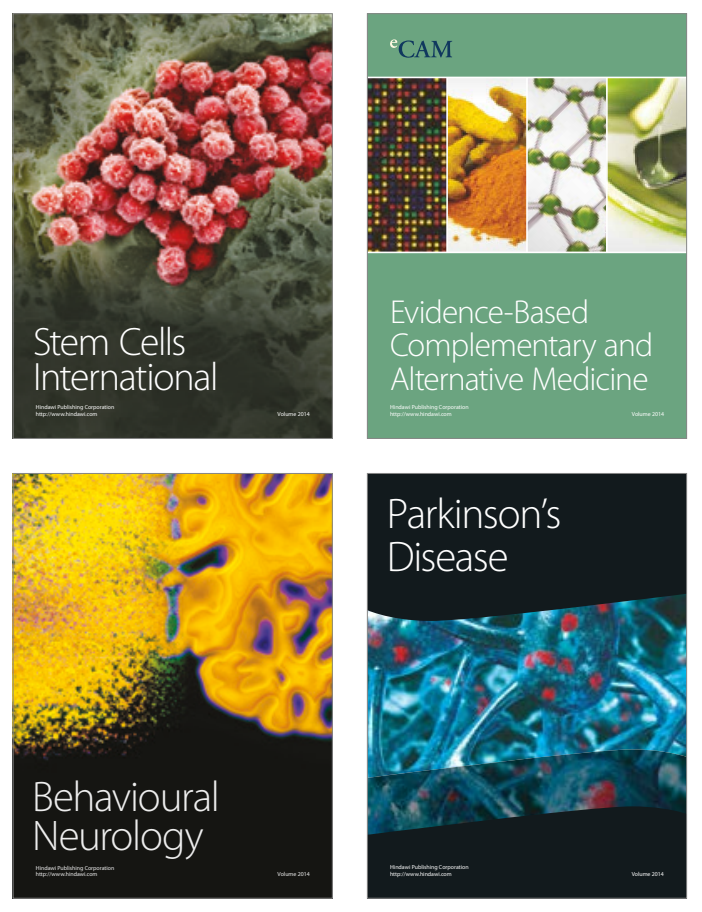
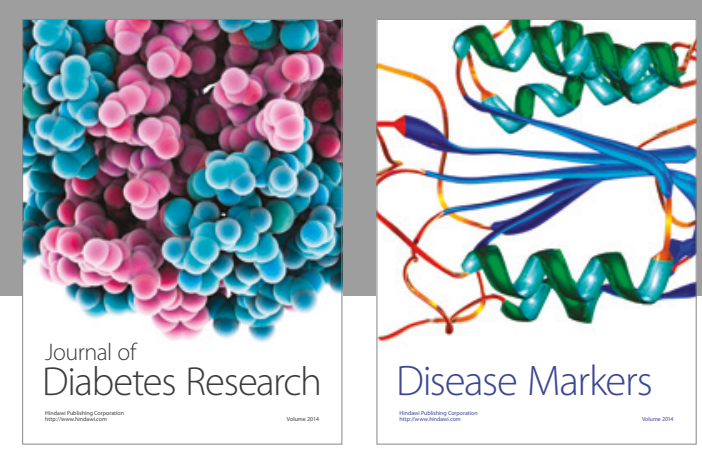

Disease Markers
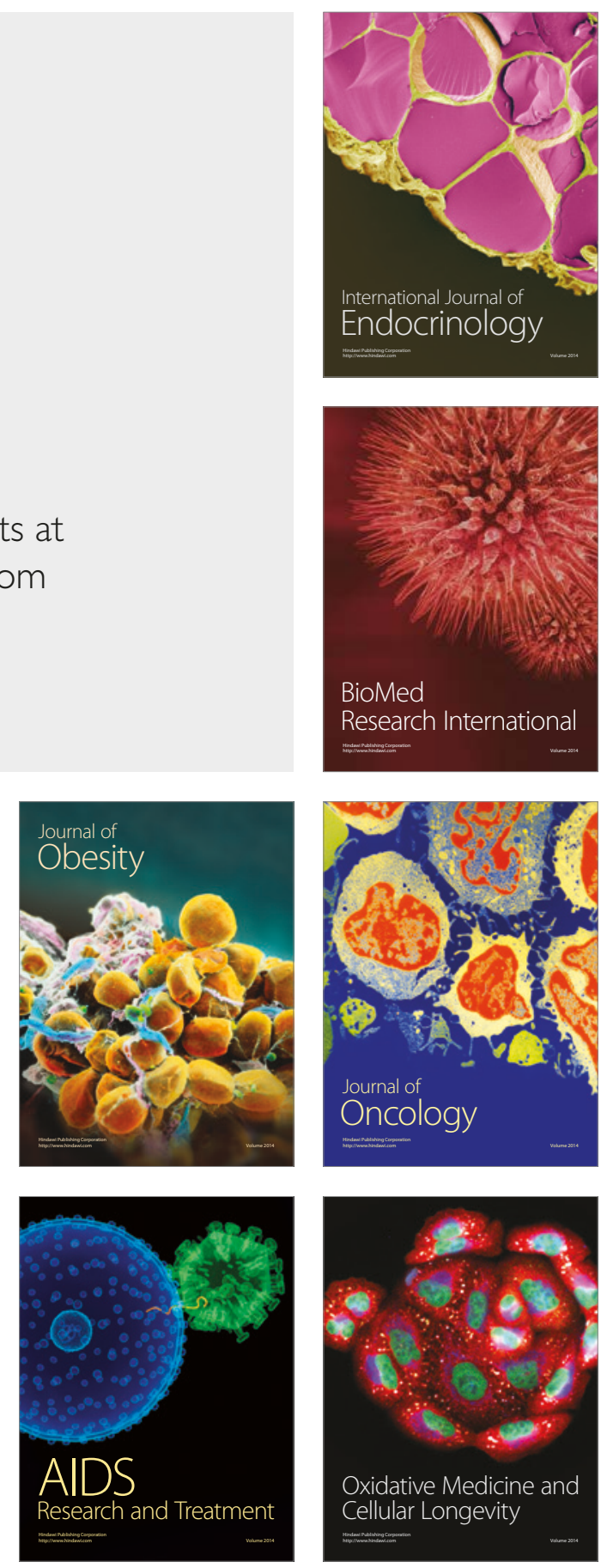